\title{
STATIC DEFORMATION OF SILICA AND SILICATES
}

Neville I. Carter \\ New Haven, Connecticut}

This paper reviews the static ductile deformational processes in

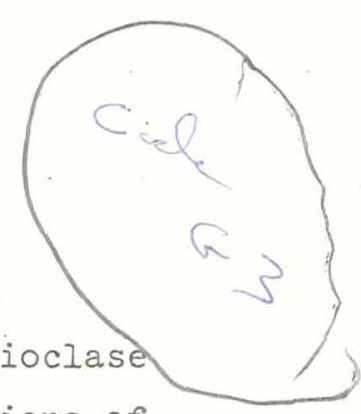

naturally and experimentally deformed quartz, olivine, pyroxenes and plagioclase
as determined by many workers primarily in the last decade. The orientations of deformational lamellae in experimentally deformed quartz vary with temperature, pressure and strain rate but, as predicted by the experiments, lamellae of only one orientation (subbasal I) are similar in all respects to most natural lamellae. The slip systems in olivine change with increasing temperature and pressure and decreasing strain rate from (100), \{110\}[001] through $\{0 k 1\}[100]$ to (010)[100]. At a natural strain rate of $10^{-14} \mathrm{sec} .^{-1}$ the $\{0 \mathrm{kl}\}[100]$ system observed in most peridotites should operate at temperatures above about $300^{\circ} \mathrm{C}$ at low $(3-5 \mathrm{~kb})$ pressures. Orthopyroxenes in rockekommonly deform by kinking on the system $\{100\}[001]$ but this mechanism is observed in experiments only at very high temperatures and low rates, deformation under other conditions being accompanied by a martensitic inversion to clinopyroxene. The slip vs. transformation boundary is strongly temperature and rate as well as stress dependent and the transformation should not take place in nature at temperatures above about $500^{\circ} \mathrm{C}$. Experimentally deformed clinopyroxenes twin on $\{001\}[100]$ at the lower temperatures and higher rates giving way at higher temperatures and lower rates to twin and translation gliding (in opposite sense) on $\{100\}[001]$; the latter mechanisms are dominant in tectonites. Plagioclases are rarely deformed in tectonites but experiments on those of various composition and structural states have produced albite and pericline twinning, \{010\} slip, and subbasal lamellae.

The best understood of the recovery processes, polygonization, has been observed in both experimentally and naturally deformed quartz, olivine and enstatite. Polygonization, leading to the formation of subgrains having small disorientations, occurs by the diffusion-controlled process of aislocation climb. Dry creep experiments on peridotite have shown the polygon size in olivine to be dependent on stress. The analysis leads to an estimate of $1 \mathrm{~kb}$ stress difference during polygonization of olivine in certain xenoliths although small concentrations of $\mathrm{H}_{2} \mathrm{O}$ might lower this estimate appreciably.

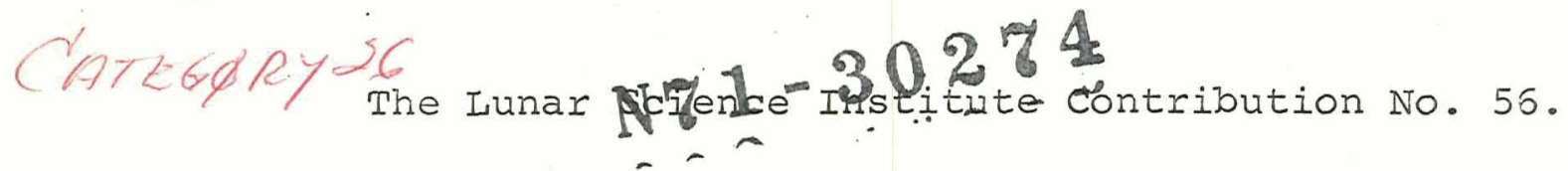


Syntectonic recrystallization of $\alpha$-quartz aggregates in axially symetric experiments give $c\|\| \sigma_{1}$ at low temperatures and high rates changing contimuously to small circle girdies $\left(25^{\circ}\right.$ to $\left.50^{\circ}\right)$ about $\sigma_{1}$ at the higher temperatures and lower rates. Crossed girdle fabrics, similar to those commonly observed in quartz tectonites, were produced in the $\alpha$-field at high temperatures in experiments in which the stress and strain fields were not axially symetric. Quartzaggregates recrystallized in the $\beta$-field develop composite $c\|\| \sigma_{1}+c \perp \sigma_{1}$ fabrics. Experimental syntectonic recrystallization of both olivine and enstatite aggregates gives $\underline{b} \| \sigma_{1}$ with $\underline{a}$ and $\underline{c}$ girdles in the $\sigma_{2}=\sigma_{3}$ plane, fabrics also common to naturally deformed peridotites. However, in natural deformations in which $\sigma_{1} \neq \sigma_{2} \neq \sigma_{3}$, a (OI) probably develops parallel to $\sigma_{3}$ as may a (opx) in accord with predictions of the elastic anisotropy hypothesis.

The deformational processes induced by static and dynamic deformation of silica and silicates are compared briefly; the processes operative in tectonites are readily distinguished from those produced by shock deformation. 
Microstructures and fabrics of statically deformed rocks may provide important clues as to physical conditions during deformation and to the tectonic history of the naterial. Many of the relevant data can be obtained directly by optical, $x$-ray and electron microscope studies of the rock specimens themselves but these data must be evaluated with reference to controlled laboratory experiments. The purpose of this paper is ta summarize the results of relevant deformation experiments on quartz, olivine, pyroxenes and plagioclase and assess the extent to which processes operative in the experiments have also been active in natural deformations. Because of space limitations, I shall omit a discussion of fracture of the materials and will treat only, in turn, the processes of plastic deformation, recovery, and recrystallization. It is, of course, essential to distinguish between effects due to static and dynamic deformation in order to interpret properly the data obtained from studies of deformational features in rocks. While both types of deformation are clearly important, particularly in Iunar studies, it is the static deformation that will ultimately provide information concerning the tectonic history and thermal evolution of terrestrial planets.

Appreciable advances in the understanding of the behavior of the strong brittle silicates have been made in the last decade mainly by David $T$. Griggs, his students and colleagues, and through the advent of solid medium high pressure deformation apparatus designed by Griggs and gas apparatus designed by Griggs and II. C. Heard. Some progress in determining the deformational processes has come from applications of standard methods of structural petrology but relatively new optical techniques, such as those by Turner et al., (1954), Christie et al. (1964), Raleigh (1965) and Carter and Ave'Lallemant (1970), have allowed systematic determinations of the plastic deformation mechanisms. Certain $x$-ray techniques, developed primarily by metaliurgists, have just recently been adopted in studies of substructure and fabrics of the deformed materials. The most important contribution has been the adaptation of $x$-ray texture goniometry to determinations of complete fabrics of recrystallized silica and silicate aggregates by Baker et al., (1969) as best exemplified in the quantitative studies of quartz preforred oxientations by Green et al. (1970). Replication electron microscopy was first used in these materials to confirm the hypothesis that basal deformation lamellae in experimentally deformed natural quartz were composed of arrays of edge dislocations (Christie et al., 1964). However, more recent transmission electron microscopy 
(McLaren et al., 1967) of the specimens showed directly that the dislocations were of a mixed type and that they were commonly associated with mechanically induced basal Brazil twins. The routine use of these new and powerful tools in future studies of rock deformation will certainly lead to changes or refinements in determinations of the deformational processes and their dependences on the pinsical variables/summarized below.

\section{PLASTIC DEFORMATION}

$\underline{\text { Quartz }}$

For nearly half a century it has been recognized that quartz deforms readily in nature as evidenced by the ridespread occurrence of extinction bands comnonly oriented subparallel to the $c$-axis and deformation lamellae generally inclined at $10^{\circ}$ to $30^{\circ}$ to $\{0001\}$ (subbasal lamellae). The deformation lamellae are subparaliel, planar or lenticular features that are asymmetrical and are more evident in phase contrast (Fig. IA) than in bright-field illumination unless they contain the common minute brownish cavities or inclusions. Experimental plastic deformation of natural quartz was first achieved in the early 1960's (Carter et al. s 1961, 1964; Christie et al., 1964; Christie and Green, 1964; Griggs and Blacic, 1964) when it was shown that quartz slips easiest on the $\{0001\}$ plane parillel to an a-axis at temperatures to $\mathrm{ca} .700^{\circ} \mathrm{C}$, above which slip on $\{10 \overline{0} 0\}$ parallel to $c$, $\underline{a}$, or $<\underline{c}+\underline{a}>$ dominates. Basal deformation lamellae, similar in optical properties to natural lamellae, were shown to be due to photoelastic effects produced by long range stresses from trapped mixed deslocation arrays (Christie et al., 1964; McLaren et al., 1967). Bending of the crystal structure from inhomogeneous slip on $\{0001\}$ gave rise to extinction bands subparallel to $c$, similar to those in naturally deformed quartz. Recently, experiments on synthetic quartz crystals of varying OII and impurity contents have shown that the quartz flows readily at relatively low stresses and temperatures in the presence of small but critical or concentrations (Griggs and Blacic, 1965; Griggs, 1967; McLaren and Retchrora, 1969; Baëta and Ashbee, 1969a,b, 1970a,b).

Subbasal lamellae, identical in both optical properties and crystallographic orientation to most natural lamellae (Fig. IB,C) were first produced in experiments by Feard (1962) and in more extensive recent experiments (Heard and Carter, 1968; Christie et al., 1968; Ave'Lallemant and Carter, 1971). The lamellae orientations, as functions of pressure and temperature, are shown in Figure 2 and synoptic histograms showing the basis for division into the various subfields are given in Figure 3 (Ave'Lallemant and Carter, 1971.). Five fields of lamellae orientations have been recognized and the boundaries of these fields are rather 
strongly dependent on pressure, temperature and strain rate: (l) basal - a very large percentage of the lamellae are inclined at less than $6^{\circ}$ to $\{0001\}$; (2) prismatic - many lamellae are aligned at within $10^{\circ}$ of the c-axis with a submaximum at $0^{\circ}$ to $15^{\circ}$ to $\{0001\}$; (3) subbasal II - a maximum at $5^{\circ}$ to $10^{\circ}$ to $\{0001\}$ with a submaximum nearly parallel to $c$; (4) subbasal I - a maximum between $10^{\circ}$ and $30^{\circ}$ with a submaximum nearly parallel to the prism; and (5) relatively nonselective the lamellae form at all orientations. There are gradations between some of these fields, especially the prismatic-subbasal II fields, and the "relatively non-selective" field (not shown) overlaps the subbasal I and II and prismatic fields. A comparison of these histograms with that for natural lamellae (Fig. 3F) shows that only the non-rational lamellae of subbasal I orientation are commonly produced by tectonic deformations.

Figure 4 shows the relative orientations of various subfabric elements in specimens containing subbasal. I lamellae produced experimentally ( $A, B, C)$ and. naturally (D, E, F; Carter and Raleigh, 1969). In the experimentally deformed specimen the lamellae form at angles near but most commonly less than $45^{\circ}$ to $\sigma_{1}$ (N-S arrows). The $\subseteq$ axes in the more highly deformed (more profuse lamellae) parts of individual grains (Fig. 4B) lie closer to $\sigma_{1}$, the maximum principal compressive stress, than those in less deformed parts (open circles) and poles to lamellae (points of arrows, Fig. 4C) lie nearer $\sigma_{3}$ than do the c-axes (ends of arrows). Similar relative orientations of the subfabric elements are evident for the natural. tectonite (Fig. 4D, E, F) leading to the interpretation of orientations of principal stresses shown (solid one percent circles) which are confirmed by analysis of calcite twins (dashed one percent circles; Carter and Friedman, 1965). Thus, subbasal I lamellae produced in the experiments are virtually identical to those observed in statically deformed quartz-bearing rocks.

In Figure 5 the results of Heard and Carter (1968; $T-\dot{\varepsilon}$ space) and. Ave'Lallemant and Carter (1971; T-P space) are combined into a three-dimensional diagram along with a possible continental geothermal gradient (Clark and Ringwood, 1964). At a representative geological strain rate of $10^{-14} / \mathrm{sec}$, subbasal I lamellae should develop under most crustal conditions, as observed. Basal deformation lamellae seem to be common only to quartz-bearing rocks shocked to high pressures by meteorite or comet impact (Carter, 1968). The natural counterparts of the remaining orientations produced experimentally have not yet been discovered in tectonites.

The origin of these non-rational subbasal lamellae is still unknown and the solution will require extensive studies employing transmission electron microscopy. They may originate by interactions of basal and prismatic dislocations with 
recently discovered basal Brazil. (Mciaron et al., 1967) and 1)auphine' (14ilis, 1970 ) deformation twins or impurity concentrations(Ave'Lallemant and Carter, 1971) and/0r they may originate by dislocation climb or cross-slip (Christie et al.; 1968).

Olivine

Deformation of olivine has been the subject of recent intensive study because of the expected dominance of this mineral in the upper mantle and because of the Iikelihood that flow in the hot upper mantle is primarily responsible for the changing positions of continents and their first-order structures. Kink bands, such as those shown in Figure ID, have been recognized as indicators of plastic deformation for some time (e.g., Turner, 1942). More recently, Raleigh (1968) and Raleigh and Kirby (1970) have shown that most naturally produced kink bands in olivine originate by translation gliding parallel to the [100] axis in nearly any plane in the f0kl]zone (Fig. 6). That is, the slip system $T$ (slip plane) $=$ (okl\}and $t$ (slip direction) $=$ [100] (hereafter referred to as $\{\mathrm{hkl}\}[\mathrm{uvw}$ ] is indicated by rotations of the crystal structure during inhomogeneous slip (see e.g., Thrner et al., 1954; Raleigh, 1968 ). Griggs et al. (1960) first deformed olivine experimentally but most of the work on plastic deformation of olivine has been accomplished by Raleigh (1963, 1965, 1967, 1968), Raleigh and Kirby (1970) and Carter and Ave'Lallemant (1970). In the recent experiments, deformation lamellae (Fig. IF), identical to those produced in quartz, form below about $1000^{\circ} \mathrm{C}$ and are parallel to the active slip planes(Raleigh, 1968). At temperatures above $1000^{\circ} \mathrm{C}$, at a strain rate of about $10^{-5} / \mathrm{sec}$, these lamellae are no longer present presumably because thermal agitation is sufficient to allow the dislocations to climb (see section on polygonization). Photoelastic lamellae are also very rare in tectonites because the long times available for the climb process does not necessitate the high temperatures required in the laboratory. Artifical lamellae were, however, produced in the high temperature experiments by allowing metal particles, induced along grain boundaries before the experiments, to diffuse along dislocation lines during the experiments (Carter and Ave'Lallemant, 1970) thus producing aligned planes of opaque particles parallel to the slip plane (Fig. IF). The presence of lamellae in olivine allows a more precise means of determining the orientations of the slịp systems as functions of the physical variables than does the measurement of rotations alone.

The slip systems in experimentally deformed olivine determined in the manner described above, as functions of temperature and strain rate, are show in Figure 7 (Carter and Ave'Lallemant, 1970). The systemskhange with increasing temperature and decreasing strain rate from \{110\} [001] through \{0ki\} [100] to (010) [100], the first two of these confirming the earlier results of Raleigh (1968). The important $\{0 k 1\}[100]$ system that predominates in natural deformation/has been 
Iikened by Raleigh to a pencil glide mechanism in which the plane in the [100] zone having the highest shearing stress becomes the active slip plane.

The boundaries of the slip fields, in addition to being dependent on temperature and strain rate, appear also to be dependent on pressure. (Carter and Ave'Lallemant, 1970) but in a much more systcmatic way than for quartz. The synoptic diagram in Figure 8 shows the pressire dependence, determined experimentally to $20 \mathrm{~kb}$, as well as temperature and strain rate dependence, extrapolated to higher pressures and lower rates. Included on the diagram is a possible oceanic geotherm (Clark and Ringwood, 1964). At a representative geological strain rate of about $10^{-14} / \mathrm{sec}$. and at low pressures $(3-5 \mathrm{~kb}),\{0 \mathrm{k} 2\}$ [100] slip should take place at temperatures above about $300^{\circ} \mathrm{C}$ and (010) [100] slip above about $500^{\circ} \mathrm{C}$. These temperatures decrease with increasing pressure but because of the rapid increase in temperature along the geotherm, processes involving diffusion, such as polygonization and recrystallization, probably predominate at greater depths.

\section{Pyroxene}

\section{Orthopyroxene}

Orthopyroxene in tectonites commonly has deformed by kinking (Fig. 9A) due to inhomogeneous slip on the system \{100\} [001]. However, in many deformation experiments on enstatite over a pressure range of 5 to $40 \mathrm{~kb}$, temperatures from $27^{\circ}$ to $1000^{\circ} \mathrm{C}$, the orthopyroxene in deformed zones has transformed to cinopyroxene (Griggs et al., 1960; Turner et al., 1960; Borg and Handin, 1966; Riecker and Rooney, 1967; Raleigh, 1965, 1967). These studies have shown that the transfomation is sensitive to shearing stresses. The orthoenstatite-clinoenstatite inversion requires a shear through 13.3 or $18.8^{\circ}$ parallel to [001] in the $\{100\}$ plane; the transformation is nearly displacive with little or no volume change and involves breaking only half of the $\mathrm{Mg}-\mathrm{O}$ bonds and none of the Si-O bonds (Coe, 1970). For this reason, as pointed out by Raleigh et al. (1971) the transformation should have a low energy of activation as compared with translation gliding on $\{100\}[001]$ in which the atomic barriers to slip are sumounted by means of themal agitation. Therefore, the translation gliding process should be that favored at the higher temperatures and lower rates of deformation.

Although commonly produced in the deformation experiments, the transformation orthoenstatite-clinoenstatite is extremely rare in naturally deformed rocks; it has been well documented only in a mylonite from Australia (Tromsdorf and Wenk, 1968). In an attempt to resolve this enigma, Raleigh et al. (1971) carried out a series of experiments on pyroxenite and therzolite at temperatures ranging from $800^{\circ}$ to $1450^{\circ} \mathrm{C}$, pressures from 5 to $20 \mathrm{~kb}$, and strain rates from abont 
$10^{-2}$ to $10^{-7} \mathrm{sec}^{-1}$. The results (Fig. 10) indicate that at a given strain rate there is a critical temperature above which the enstatite slips instead of transforming and that the boundary between the two processes is strongly dependent on both temperature and strain rate. As preaicted, the apparent activation energies for the transiormation and slip processes, determined by a temperature differential creep method, were about 10 and $70 \mathrm{kcal} / \mathrm{mole}$, respectively (Raleigh et al., 1971).

In addition to the strong temperature and strain rate dependence of the transformation, it also appears to be dependent on stress, as observed by earlier workers. When the stress dependence and activation energies for both the slip and transformation processes are determined (Raleigh et 2l., I971), it is possible to predict the boundary in stress, strain rate, and temperature space. The predicted boundary (dashed line in Figure 11), when projected onto the strain rate-temperature surface agrees well with the experimentally determined boundary between the slip and transformation fields. Both the predicted and experimentally determined boundaries are extrapolated, in Figure 11, to the lower rates expected of natural deformations; the boundaries are curved and become asymptotic to the -log $\dot{\varepsilon}$ axis at low temperatures, an expected result for competing rate processes (Raleigh et al., 1971). The extrapolation indicates that enstatite deformed in tectonites should slip rather than transform at temperatures above about $500^{\circ} \mathrm{C}$. The transformation observed in the mylonite from Australia might well be attributed to high strain rates and/or stresses and it is suggested (Raleigh et al., 1971) that clinoenstatite may have no true stability field.

Clinopyroxene

Clinopyroxenesin tectonites have commonly deformed by mechanical twinning and they are commonly kinked in zones nearly normal to [001]. The twin-glide system generally observed is \{100\}[001] but minor twinning on \{001\}[100] sometimes accompanies the dominant system (Fig. 12). Griggs et al. (1960) first deformed diopside experimentally at $5 \mathrm{~kb}$ snd $500^{\circ} \mathrm{C}$ and found evidence for twingliding on $\{001\}[100]$ as well as translation gliding on $\{100\}[001]$. In more extensive experiments on diopside, Raleigh and Talbot (1967) found that twins on $\{001\}$ were dominant at the lower temperatures and higher strain rates and that these gave way to $\{100\}$ twins and translation gliding (shear in the sense opposite to twinning) at the higher temperatures and lower rates. The temperature vs. strain rate fields of the various deformation mechanisms of the clinopyroxenes have not been adequately delineated by experiments to date. 
Plagioclases in tectonically deforned rocks only rarely contain structures that can be attributed unequivocally to mechanical deformation. Seifert (1965) found kink bands oriented normal to $\{010\}$ in naturally deformed plagioclase (Fig. 9D) and deduced that the kinking originated by translation gliding parallel to $\{010\}$. Mugge and Heide (1931), and later Starkcy and Brown (1964), produced mechanical albite and pericline twins in anorthite experimentally although in the latter study, most of the twins disappeared upon removal of the load ("elastic twins"). Laves (1952) also produced "elastic twins" by indentation of high albite. Borg and Handin (1966) were the first to induce permanent albite twins in labradorite, at $5 \mathrm{~kb}$ confining pressure and $500^{\circ} \mathrm{C}$. In one crystal, mechanically induced twinning was restricted to a narrow zone and the resulting external rotation gave rise to a well-defined kink band.

In more recent experiments at 5 to $10 \mathrm{~kb}$ confining pressure and $25^{\circ} \mathrm{C}$ to $800^{\circ} \mathrm{C}$ on plagioclases of various compositions and structural states, Borg and. Heara (1970) have produced twin-gliding, translation gliding on $\{010\}$ and subbasal deformation lamellae. Both albite and pericline twinning were produced in plagioclase of the composition range $\mathrm{An}_{30^{-}} \mathrm{An}_{95}$ (except $\mathrm{An}_{44_{4}}$ ) at $800^{\circ} \mathrm{C}$ and $10 \mathrm{~kb}$; in parts of crystals where one twin law had operated exclusively, kinking also occurred. Slip on $\{010\}$ was produced in low albite at $800^{\circ} \mathrm{C}$ and in peristerite $\left(\mathrm{An}_{23}\right)$ under a variety of conditions. These crystals were not favorably oriented for albite twinning and slip appears to have occurred on $\{010\}$ in the same direction but opposite sense to that required for albite twinning. Irrational subbasal deformation lamellae, similar to those in quartz, were produced in planes of high shearing stress at $700-800^{\circ} \mathrm{C}$ at $10 \mathrm{~kb}$ in experiments on crystals of composition $\mathrm{An}_{37}, \mathrm{An}_{44}$ and $\mathrm{An}_{77}$

The yield strengths of the single crystals oriented for twinning are quite high, about $2 \mathrm{~kb}$ at $800^{\circ} \mathrm{C}$, with the strengths of polycrystalline aggregates being up to three times greater (Borg and Heard, 1970; see also Seifert, 1969). This may account for the rarity of deformation in plagioclase of tectonites although some of the aloite and pericline twins commonly observed cannot be excluded as deformation twins. However, there exists no definitive way of distinguishing growth twins from deformation twins, and it appears that evidence for deformation of plagioclase (or lack of it) will shed little light. on the tectonic history of naturally deformed plagioclase-bearing rocks. 
The plastic deformation processes described above, operating alone, generally lead to work-hardening; that is, the stress required to produce slip and twinning increases with increasing strain. This is mainly because of: (a) disiocation interactions and interference of slip dislocations moving on aifferent slip systens (especially interstcting screw dislocations); (b) obstacles to slip such as impurity atoms, glide polygon boundaries, and grain and subgrain boundaries; and (c) inhomogeneous slip giving rise to extinction bands. Work-hardening can be removed and steady state flow (constant stress and constant strain rate) achieved by the process of self-diffusion, which is promoted by high temperatures and/or low strain rates. That is, steady state flow is achieved under conditions at which the rate of work-hardening is equal to the rate of recovery. Because of the very long relaxation timeshavailable in natural deformations, it is expected that such steady state flow prevails.

One way in which crystals and aggregates can soften and deform by steady state flow is by the process of recrystallization, which will be discussed in a subsequent section. However, it is observed that, at teraperatures lower than those required for recrystallization, crystals and aggregates can soften by one or several processes collectively termed recovery. Most of these processes are poorly understood but they must involve reductions of internal stresses generated by interactions and intersections of dislocations and their pile-up at barriers. At high temperatures, grain boundaries can migrate and dislocation loops can contract and disappear. Edge dislocations may climb, meet dislocations of opposite sign and annihilate, or they may rearrange into more stable, lower energy configurations.

The best understood recovery process is that of polygonjzation (Cahn, 1951) which has been well documented in such diverse materials as metals, ceranics, marble (Heard, 1968) and halite (e.g. Amelinckx, 1954; Carter and Heard, 1970 ). Edge dislocations of one sign are created by bending the crystal structure (Fig. I3A). At sufficiently high temperatures or low strain rates, the dislocation lines may absorb or emit atomic vacancies by diffusion and climb vertically out of their slip planes. The dislocations may then rearrange into walls that separate virtually strain free domains having small disorientations (Fig. 13B,D), markedly reducing the strain energy of the crystal. For slip. on a single system, the polygon boundaries are nearly normal to the slip vector, but for multiple slip, interactions between dislocation walls may lead to more irregular orientations of the boundaries (Fig. 13C; Amelinckx and Strumane, 1960). This diffusioncontrolled process may occur during annealing or it may take place during steady 
state creep.

Polygonization has recently been found in experimentally deformed quartz (Hobbs, 1968; Green et al., 1970), olivine (Raleigh and Kirby, 1970; Carter and Ave'Lallemant, 1970) and enstatite (Raleigh et al., 1971) and similar structures are common in naturally deforned counterparts. Particularly striking examples of polygonization in experimentally and naturally derormed olivine have been illustrated by Raleigh and Kirby (1970). The polygonal structure is welldeveloped in olivine in a xenolith from Lunar Crater, Nevada (Fig. 14A) and in olivine in a lherzolite deformed at a constant stress of $9.5 \mathrm{~kb}$ at $1270^{\circ} \mathrm{C}$ and a strain rate of $10^{-4} / \mathrm{sec}$. (Fig. $24 \mathrm{~B}$ ). The subgrains in both specimens tend to be rectangular with the boundaries approximately parallel to (100) and (001). The disorientations across the boundaries are generaliy Iess than $5^{\circ}$ as is the case for polygonization in experimentally deformed quartz (Hobios, 1968).

Creep experiments on metals and alkali halides have shown that, in general, the size of subgrains varies inversely with stress (e.g. Sherby and Burke, 2968; Weertman, 1968, 1970). A similar tendency has been observed by Raleigh and Kirby (1970) for olivine in therzolite deformed at constant stress differences of 9.5 and $4.6 \mathrm{~kb}$. The average dimensions of the subgrains, measured parallel to (100) and (001), were plotted on a log-log I vs. $\mu / \sigma$ diagram (Fig. 15) in accord whth the empirical relation $I=I_{0} \mu / \sigma$ found for other materials (Weertman, 1968, 1970) where $I_{0}$ is a constant and $\mu$ is the shear modulus. Also plotted on the parallel Iines drawn through the experimentally detemined points are the average dimensions of (100) and (001) of the larger subgrains in olivine in the xenoliths from Lunar Crater and Ilawaiian basalts (Fig. 15). The analysis leads to an estimate of about I ko differential stress during polygonization of the naturally deformed olivine. This estimate seems high in view of recent results from experimental steady state deformation of olivine (Raleigh and Kirby, 1970; Carter and Ave'Lallemant, 1970). However, the creep experinents were conducted dry and small amounts of $\mathrm{H}_{2} \mathrm{O}$, such as reasonably occur in the upper mantle, should lover the experimental stress for a given polygon size and lead to lower estimates of the natural stress differences. When the effect of $\mathrm{H}_{2} \mathrm{O}$ concentration has been adequately investigated, stuaies of polygonization may well provide a powerful means for estimating the stress differences during natural creep.

\section{RECRYSTALIIZATION}

Since the initial development of the field of structural petrology by Sander (1930) and Schmidt (1925) it has been recognized that minerals in tectonites commonly have strong preferred orientations and that the fabrics are 
related in symmetry to other subfabric clenents of the deformed rocks. In the early interpretations, plastic defornation was regarded as the most likely orienting mechanism for silica and some silicates although, for quartz, fracturing into crystallographically controlled needles and subsequent mechanical rotation was postulated. However, there is little evidence to substantiate these hypotheses and it is becoming increasingly evident that syntectonic recrystallization (hot-working) is the dominant orienting process. Syntectonic recrystallization, the growth during deformation of new strain-free grains with medium to large-angle boundaries is a very efficient orienting or reorienting process as very strong preferred orientations can be produced under very small stresses and strains. Furthermore, very large creep strains can be achieved by recrystallization and/or grain boundary migration (Packer and Sherby, 1967) as has been demonstrated for a class of ductile metals termed "superplastic" in which tensile strains greater than 1000\% have been produced. The minimum temperature required for recrystallization depends on the nature of the material, strain energy, strain rate and chemical environment; the driving force appears to be internal strain energy and/or grain or subgrain boundary energy. Annealing recrystallization, in contrast to syntectonic recrystallization, occurs under hydrostatic pressure and may alter fabrics produced by other means; the orientation of the new grains are generally controlled by the orientations of the host crystals.

Of the various minerals in tectonites, quartz has received most attention and Sander (1930) showed that the quartz c-axis fabrics form restricted but overlapping groups of patterns. These fabric types have been reviewed by Fairbairn (1949) and more recently by Sylvester and Christie (1968) and Green et al. (1970). The most common fabrics have girales with maxima nomal to the tectonic b-axis and crossed girdles, with orthorhombic symmetry, nearly symetrical to lineations and nomals to foliations. Much rarer are smallcircle girales about the pole to foliation and inclined at $25^{\circ}$ to $50^{\circ}$ to it and point maxima fabrics in some granulites in which the c-axes are concentrated normal to the foliation. Recrystallized oivine also shows strong orientations; the comnonest fabric type has an $\alpha=\underline{b}$ point maximum nomal to a mineral flattening foliation which contains $\beta=\underline{c}$ and $\gamma=\underline{a}$ girdles. Some olivine-bearing tectonites have lineations resulting from mineral elongations and these are most. commonly parallel to concentrations of $\gamma$-axes. Other fabric types also occur: for a review, see den Tex (1969) and Ave'Lallemant and Carter (1970). Oxthopyroxenes and clinopyroxenes in deformed peridotites also slow preferred orientations that were probably produced by syntectonic recrystalizization. 
Bxperinental syntectonic recrystallization of quartz aggregates was first produced by Carter et aI. (1964) and Raleigh (1965) and more recentiy in the systematic study of Green et al. (1970). Raleigh (1963) first produced syntectonic recrystallization of olivine and this has since been accomplished in more extensive experiments by Ave'Iallemant and Carter (1970). The writer has recently recrystallized both enstatite and diopside under stress in a sexies of prelininary experiments. In general, two types of starting material have been used for most of these recrystallization experiments: (a) coarse-grained natural aggregates of orthoquartzite, dunite and lherzolite; and (b) very fine-grained natural aggregates of flint and novaculite or compacted pellets of ground olivine, enstatite and diopside. In the coarse-grained aggregates, recrystaliziztion is general. Iy preceded by polygonization and by the development of serrate grain boundaries presumably by their migration. At higher temperatures new nuclei appear first at grain boundaries and then along kink bands or other regions of high strain energy in the host crystals (Fig. 14C). Grain boundary recrystallization advances until the old grain is consumed and is followed by the growth of grains oriented suitably with respect to the stress, forming a new rock (Fig. I4D) with irregular to polygonal, optically homogeneous grains (Ave'Lallemant ard Carter, 1970).

Coarse-grained quartzite specimens compressed at high temperatures to high strains $(>50 \%)$ develop textures analogous to those in quartz mylonites (Fig. I4F; Carter et al., 1964; Blacic and Griggs, 1965; Thllis, 1968). Ribbons of fine-grained recrystallized quartz wrap around relict quartz augen flattened to varying degrees. Studies of the preferred orientations of these augen by Blacic and Griggs (1965) and Tullis (1968) indicate that the least defomed ones are oriented with $\subseteq \| \sigma_{I}$, as expected if slip has occurred primarily on the basal and prism planes.

Recrystallization. in the fine-grained aggregates is evidenced by enlargement of grains; Figure $14 \mathrm{E}$ shows a specimen in which the centraI recrystalized section is very coarse-grained by comparison with the starting material $(<37 \mu)$ at the ends of the specimen. Depending on the conditions of recrystallization, the new grains may be equant or they may be clongated nomal to $\sigma_{1}$, as is true for most grains in the samples shown in Figures $24 \mathrm{D}$ and $\mathrm{E}$. The temperature of onset of recrystallizationf decreasing strain rate and probably also with increasing strain energy. The presence of $\mathrm{H}_{2} \mathrm{O}$ lowers the temperature of recrystallization of quartz (Green et al., 1970) and it increases the rate of recrysulalization and promotes larger grain size in both quartz and olivine. 
presumably by enhancing diffusion (Hobbs, 1968; Green et al., 1970).

Fabrics of the syntectonically recrystallized specimens

Quartz

Green, Griggs and Christie (1970) recrystallized flint and noveculite during deformation in both $\alpha$ and $\beta$ stability fielas over a wide range of pressure, temperature and strain rate conditions. The diagrams in Figure $16 \mathrm{~A}-\mathrm{E}$ shov only some of their optically determined c-axis fabrics but they also obtained complete inverse pole figures for most of their specimens using the $x$-ray method of Baker et al. (1969). Figure 17 shows their results for the $\alpha$-quartz stability field. At the lower temperatures and higher strain rates at which recrystaliziation occurs,

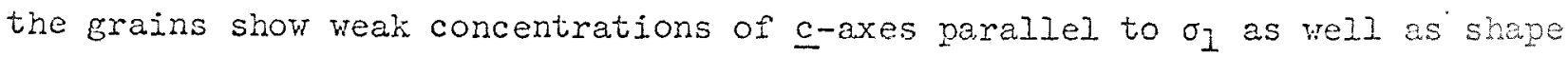
elongations nomal to $\sigma_{1}$ and they comonly contain features induced by plastic deformation. At the highest temperatures and lowest strain rates, the $c$-axes form a small circle girdle about $\sigma_{1}$ (Fig. I6A) with $\underline{x}$ \{10II\} oriented preferentially parallel to $\sigma_{1}$; in these specinens the grains are larger and more nearly equant and strain free than those fomed at the lower temperatures. As pointed out by Green et al. (1970), the Dauphine' twinning mechanism discoverca by Tullis (1970) is probably responsible for the parallelism of $\underline{r}$ and $\sigma_{1}$ and may have little to do with the recrystalization process responsible for the pattern of c-axes. There appears to be a smooth transition in fabric, with increasing temperature and decreasing strain rate, from $c \| \sigma_{1}$, through a composite $e_{1} \sigma_{1}$ th $\underline{x} \| \sigma_{1}$ fabric, to the $\underline{r} \| \sigma_{1}$ fabric. Annealing these syntectonically recrystalizied specinens increases the grain size, removes the intragranular strain features and leads to more equant grain shapes. The annealing caused little change in the r-maximum fabric, strengthened the $e \| \sigma_{1}$ fabric two-fold, and nearly eradicated the $c\|\| \sigma_{1}$ component of the composite fabric (Green et al., 1970).

Crossed girdle fabrics (Fig. 16B) were produced in the $\underline{\underline{r}} \| \sigma_{2}$ fiela in two experiments in which inhomogeneous deformation resulted from bulging of one side of the specimen. From the nature of the bulge, Green et al. (1970) inferred that the orientation of $\varepsilon_{3} \| \sigma_{3}$ was $E-\|$ in Fig. . I6 B, $\varepsilon_{1} \| \sigma_{1}$ was $N-S a_{2 l} \varepsilon_{2} \| \sigma_{2}$ was parallel to the axis of intersection of the girdles. This fabric is nearly orthorhombic in symmetry and is very similar to crossed-girdle fabrics in naturally recrystallized quartzites. Sylvester and Christie (1968) demonstrated that, in their natural specimens with crossed girdle fabrics, the girdles also intersected in $\varepsilon_{2}$ and were symmetricaliy disposed to $\varepsilon_{1}$ and $\varepsilon_{3}$. Small. Circle girdle fabrics have also been observed in some naturally recrystallized quartzite specimens (e.g. Sander, 1930; Christie and Raleigh, 1959). It appears, therefore, 
that the textures and $\underline{r} \| \sigma_{1}$ fabrics produced experimentally in the arield have their counterparts in naturally recrystallized quartz, as is expected from a Iinear extrapolation of the boundary separating the $\underline{\underline{F}} \| \sigma_{I}$ from the composite field (Fig. 27) to the lower rates of natural deformations.

Quartz argregates recrystallized in the B-stability field (Green, 1967 ; Green et al., 1970) develop porphyroblastic textures and shov concentrations of c-axes both parallel and perpendicular to $\sigma_{1}$ (Fig. 16C,D) as was found previously by Carter (1963; Fig. 23B). In the fabric illustratea in Figure 16C, nost of the c-axes are parallel to $\sigma_{1}$, whereas in Figure $16 D$, they are concentrated both parallel and perpendicular to $\sigma_{1}$. Annealing specimens previously recrystallized in the $\beta-f i e l d$ yields larger more equant and strain free crystals and to a great strengthening of the $c\|\| \sigma_{1}$ component of the fabric (Green, 1967). Ihis observation led to the suggestion by Green et al. (1970) that the point maxima of c-axes normal to the foliation in some high grade metamorphic rocks might have originated by recrystallization in the B-stability field.

The origin of the preferred orientations in quartz has been discussed by Green et al. (1970) in light of four hypotheses advanced on the basis of extensive recrystallization work on metals: (I) selective growth of grains having stored relatively less strain energy; (2) selective growth of grains with most mobile boundaries; (3) selective growth of grains due to elastic anisotropy; and (4) nucleation of new grains with preferred orientations. The impontant I $\| \sigma_{1}$ fabrics do not seem to be consistent vith any single hypothesis although the experimental results to aate appear to favor (I) and/or (2). The $c \| o_{1}$ fabric in the $\alpha$-field is consistent with (I) above as crystals with c-axes oriented subparallel to $\sigma_{1}$ can not slip on the observed basal and prismatic systems and hence should store less strain energy than crystals at other orientations. Howcver, this mechanism is not as likely to produce similar fabrics in the B-field or the enomous strengthening during annealing because, apparently, little plastic plow occurs during these experiments. The more likely explanation, according to Green et al. (1970) is the selective growth of grains with most mobile boundaries. This suggestion may be supported by the results of their annealing experiments on bicrystals oriented so that $\sigma_{1}$ was parallel to $\subseteq$ in one $e$ nd at $45^{\circ}$ to $c$ in the other, placed one on top of the other, cold worked, and then amnealed in the

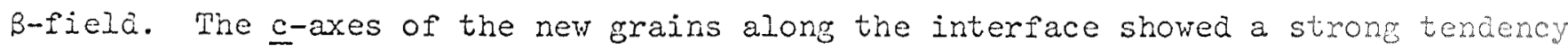

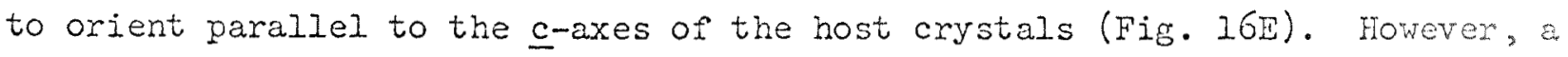
quite different result has been obtainea by llobbs (1968) in his extensive amealing, stress-annealing and syntectonic recrystallization experiments on quartz crystals. 
The c-axes of the new grains (Fig. 26F) are inclined at $20^{\circ}$ to $40^{\circ}$ to c of the host, a relative orientation nearly independent of the type of test or initial orientation of the host crystal. In addition to this difference, it is not clear why the $c\|\| \sigma_{1}$ component of the $B$-fabric is strengthened to the exclusion of the $c \perp \sigma_{1}$ component if the anmealing stress is truly hydrostatic, unless there are differences in the amount of strain energy stored in crystals of the two orientations.

\section{Olivine and Pyroxene}

The most comon olivine fabric observed in specinens from alpine-type peridotites and nodules from basalts and kinberlites is as shom in Figure 18 (Ave'Lallemant, 1967). The $\alpha=\underline{b}$ axes form a strong maximum normal to a mineral flattening foliation (great circle, $S_{L}$ ) and $\beta=e$ and $\gamma=$ a girdies with maxima lie in the foliation plane. The preferred orientations of pyroxene crystals in the peridotites have been determined in only a few stuaies and, in general, are appreciably weaker than the olivine fabrics. This is illustrated in Figure $18 B$ which shows the orientations of enstatite crystals in the same Iherzolite specimen from which the olivine measurements of Figure $18 \mathrm{~A}$ were obtained; the principal optic axes of the two minerals are subparallel.

Ave'Lallemant and Carter (1970) recrystallized dunite and olivine powàer during compression tests from $950^{\circ} \mathrm{C}$ to $1350^{\circ} \mathrm{C}$, confining pressures from 5 to $30 \mathrm{ko}$ (Fig. 19) and strain rates from $10^{-3}$ to $10^{-7} / \mathrm{sec}$. In the dunite, the orientations of new grains within the olivine host crystals (Fig. I4C) were clearly dominated by the host orientation, the individual axes being inclined at $20^{\circ}$ to $40^{\circ}$ to the host axes. A similar result was obtained previously in olivine recrystallized by kaleigh (1963) and in the quartz crystals recrystallized by Hobbs (1968). The orientations of new grains formed at relic grain boundaries are, however, related to the principal stress orientations (Ave'Lallemant and. Carter, 1970; Fig. 2C). Total recrystallization of the dunite (Fig. 14D) results in a strengthening of the stress dominatea fabric (Fig. 18C). From these observations, we concluded that grain boundary recrystallization advances until the host grains are consumed, followed by the growth of grains oriented favorably with respect to the stress field.

To eliminate the effects of host grain orieriations entirely, Ave'Lallemant and Carter (1970) dia a series of experiments on compacted pellets of potyered $(<37 \mu)$ olivine. The conditions for which grain growth was achieved are indicated in Figure 19, along with the equilibration fields of some ultramafic suites (o'Hara, 
1967). Many of the samples vere sufficiently coarse-grained (pig. I4E) that statistically significant optical measurements could be made and all of these (Fig. 19) gave fabrics similar to that shown in Figure 18D. As in the recrystallized dunite (Fi.E. 18C) a-axes concentratcd parallel to $\sigma_{1}$ are normal to a mineral flattening foliation (Figs. $14 \mathrm{D}$ and $E$ ) which contains $\beta$ and $\gamma$ girales. The underpopulated areas in the girdles of Figures $18 \mathrm{D}$ and $18 \mathrm{E}$, at about $45^{\circ}$ from the periphery, are ascribed to sampling errors inherent in U-stage measurements of optical indicatrices of fine-grained materials. The fabrics in Figure 180 are similar to most natural/Pabicics, as typified by Figure 18A, with allowances made for the fact that the stress in natural deformations need not be axially symmetric. On the basis of crystal elongations, concentrations of $y$-axes parallel to lineations. in the natural fabrics are most probably paraliel to $\sigma_{3}$; this interpretation receives some support from the orientations of the $y$-axes near melt pockets in some of the experiments (Ave'Lallemantland Carter, 2970 ). Pellets of enstatite and diopside powders have also recrystallized to aggregates somewhat finer-grainea, at comparable conditions, than has the olivine powder at companableconditions. The single diopside specimen measured to date yielded weak orientations that were not reproducible and will not be discussea. further. The results for two enstatite specimens recrystalized at $1000^{\circ} \mathrm{C}$, $15 \mathrm{~kb}$ confining pressure and a strain rate of $7.8 \times 10^{-7} / \mathrm{sec}$. are sjmilar and reproducible in fifty grain sets and so are combined and presented in Figure $18 \mathrm{E}$. As for the naturally deformed specimens, the orientations are weaker than those in olivine but the major features of the patterns are clear; the principal axes of the enstatite crystals are subparallel to those of the olivine. This similarity in ol.ivine and orthopyroxene fabrics is expected if elastic anisotropy is controlling as $\alpha=[010]$ is the most compliant axis in both minerals (Kumazawa, 1969; Hartmann and den Tex, 1964). For fabrics that are not axially symetric, presumably proauced under conditions in which the three principal stresses were unequal, the crystallographic axes should be similarly oriented but $B(01)$ shoula paraliel $\gamma(\mathrm{op} x)$ and vice versa. Such a correspondence is evident in the fabrics from the Alpe Arami garnet peridotite (Móckel, 1969). However, some of the orthopyroxene fabrics observed by Collee' (1962), Raleigh (1965), and Ave'Lallemant (1967) in naturally deformed peridotites do not appear to fit this simple scheme.

There are too few experiments at present to delineate the temperature and strain/Fatelds of recrystallization of the pyroxenes. It is clear, however, that higher temperatures and/or lower strain rates are required than for recrystallization of the olivine. In most of the experiments on Iherzolite, under aprropriate conditions, the olivine recrystalizes readily but both orthopyroxenes and 
clinopyroxenes are unaffected, deform plastically, or polygonize. rhus, in some instances, the discordant results found in olivine and orthopyroxene fabrics could be accounted for if the olivine recrystallized later than the orthopyroxene at lower temperatures in a differently oriented stress field, as sugrested previously by Helmstaedt and Anderson (1969). Alternatively, other factors, such as those discussed by Green et al. (1970) for quartz recrystallization, could. control the orientations.

\section{DISCUSSION}

The foregoing provides a summary of relevant information on static deformational processes in silica and certain silicates; we may now compare these results with the major features observed in dynamically defomed matexials. In recent years, intensive studies have been made of deformational features in silica and silicates shocked experimentally, by chemical and nuclear underground explosions, and by natural impact events. The strain rates range from about $10^{6}$ to $10^{9} / \mathrm{sec}$. and the peak shock pressures and residual temperatures vary a great deal with the structure and nature of the material as well as the shock intensity. Because of the very high strain rates, steady-state flow can scarcely be achieved and we might expect appreciable differences in deformation mechanisms from those found for tectonic deformations. Recovery and recrystallization should occur only during cooling under hydrostatic or zero stress, after the passage of the shock wave, in materials shocked sufficiently intensel hhat the residual temperatures were high.

Most is know about dynamic deformational processes in quartz and plagioclase because of their nearly ubiqitous occurrence at natural impact sites. The two minerals show very similar features during progressive shock deformation (e.g. Chao, 1968): (1) fracturing ana cleavage formation; (2) crystallographicaliy controlied faults and basal deformation lamellae in quartz and mechanical twins, deformation lamellae and kink bands in plagioclase; (3) multiple sets of planar features or "shock lamellae"; (4) solid state vitrification to dense glass which. for shocked quartz, may contain coesite and/or stishovite; and, (5) formation from a Iiquid of glass with normal density or vesiculated glass. Extension fractures are common in statically deformed quartz but cleavages and crystallographic faults are rare. Deformation lamellae parallel to \{0001\}: although comon in moderately shocked quartz, are rare in tectonites; the few that are nearly basal (Fig. 3F) in tectonites also possess the wavy or lenticular, irregular shape of subbasal lamellae, in contrast to the thin, very straight, planar basal lamellae observed in shocked quartz and some static experiments (Carter, 1965). Planar features or "shock lamellae" in quartz are most comonly" 
paraliel to $\{1013\}$ and are composed of naterial having short range order (Chao, 1963; Engelhardi et al., 1.968) along which small shearing displacements have taken place (Carter, 1968). They have been produced experimentally at shock pressures in excess of $100 \mathrm{~kb}$ (Hörz, 1968). These features are easily distinguj,shed from defomation lamellae in quartz tectonites by their strong prominence ibright field illumination and symmetrical signal in phase contrast, by their greater thickness and more planar form, by their general occurrence in multiple sets, and by their crystallographic orientation (Carter, 1965, 1968).

Plagioclase, as mentioned above, has rarely deformed in tectonites, unless some of the albite and pericline trins are due to mechanical deformation. Deformation twins are, however, definitely associated with shocked plagioclase as are deformation lamellae, planar features and kink bands (e.g. Bunch, 1968; Robertson et al., 1968, Chao, 1968). The defomation lamellae and planar features are parallel to several crystal planes of low indices and hence differ from the irrational subbasal lamellae produced in the static experiments of Bors and Heara (1970). The statically produced plagioclase aefornation lamellae also have the optical properties of subbasal quartz lameliae and therefore are easily distinguished from the planar features. Finally, kinking in the shocked plagioclase takes place by translation gliding on the $\{001\}$ plane (Bunch, 1968) as opposed to the (010\} plane found for statically deformed plagiociase (Seifert, 1965; Borg and Heard, 1970 ).

observations on dynamic deformation of olivines and pyroxenes are restricted to experiments, artificial explosions, stony meteorites and, now, Iunar materials, as natural impact events on Earth have not yet been discovered in rocks containing these minerals. Dynanically deformed olivine shows the following features with increasing shock intensity (Carter et al. 2968; James, 1969): (1) fracturing; (2) fracturing and faulting associated with local undulatory extinction; (3) planax features and a shock mosaic structuxe; (4) recrystalization and local mosaic structure; and, (5) melting. The undulatony extinction observed in olivines in the chondrites has originated predominantly by slip on the systems $\{100\},\{110\},[001]$, the high strain rate (high stress) low temperature system found in the static experiments (Carter et al., 1968). Planar features oriented near $\{100\}$ and $\{111\}$ are found in olivine from the Nevada Test site basalts and have also been observed in olivine shocked experimentaily to pressures greater than $250 \mathrm{~kb}$ by DeCarli (James, 1969). These features are associated with the mosaic structure believed to form from intense local plastic defornation accompanying partial collapse of the silica tetrahedra to six-fold coordination (Carter et. al., 1968); there is no static 
counterpart to either the planar features or shock mosaic structure. At sufficiently high shock pressures, the heavily defomed olivine crystals ameal to mosaics of small new grains, rree of strain.

With procressive shock deformation, the sequence of structures developed in the pyroxenes are similar to those observed in olivine (Janes, 1969) but higher stress levels appear to be required for their formation (Carter et al. 1968). In adition to the features described above, shocked clinopyroxenes commonly contain polysynthetic deformation twins accoraing to the system $\{001][200]$. Twins of this oxientation have been produced in static tests on diopside at high strain rate, high stress and low temperature (Raleigh and Palbot, 1967), in experimental shock defornation of particulate diopside at $250 \mathrm{~kb}$ (Sclar, 1970), in weakly to moderately shocked basalt from the Nevada Test site (James, 2969), and in shocked lunar pyroxenes. The dominant twin-gliding system in tectonically deformed clinopyroxenes and in static experiments at high temperatures and lov strain rates is $\{100\}[001]$ (Ra]eigh and Talbot, 1967).

Relatively little work has been done on dynamic deformational processes in the oxthopyroxenes but they might be expected to show the major features associated with progressive shock of olivines and clinopyroxenes. On the basis of the static experiments (Fig. 10), enstatite should transform to clinoenstatite at low to moderate shock pressures. Kink bands and lamellae of clinoenstatite are commonly observed in the enstatite of chrondritic meteorites (Raleigh, 1967) and they are believed to have formed by shock deformation. As mentioned above, the enstatite-clinoenstatite transformation has been observed in only one tectonite, a mylonite in which strain rates and stresses might well have been high.

- The brief comparisons given above indicate that, in general, there should be little dificulty in distinguishing between static and dynamic defomations in silica and silicates, on the basis of the deformational features produced. There is, as we have seen, some overlap in the dynamic mechanisms and those found in static tests at high strain rates and stresses, and lov temperatures, but this overlap virtually disappears when comparing shock-induced structures with those produce in tectonic deformations. Further delineations in $\mathrm{T}-\mathrm{P}-\dot{\varepsilon}$ space of the various slip fielas, such as the $\{001\}$ vs. \{l00\} twin-gliding fields for clinopyroxenes, will certainly improve the confidence of our interpretations. More important, however, is to acquire information on the deformational behavion and processes in silicates deformed in the strain-rate range 1 to $10 \% /$ sec; very littie relevant work has been done in this range to date. 
This paper has necessarily emphasized the deformational processes in statically defomed silica and certain.silicates, but progress has also been made in understanding their mechanical behavior. Particularly important were the discoveries that small amounts of $\mathrm{H}_{2} \mathrm{O}$ in silica and silicates may produce a drastic mechanical weakening (Griggs and Blacic, 1965; Griggs, 1967) and that dehydration of serpentine (Raleigh and Paterson, 1965) leads to brittle behavior accompanied by a large reduction in strength. According to the hypothesis of Griggs and Blacic (1965) and Griggs (1967) the water-weakening in silica and silicates results from hydrolyzing Si-O-Si bxidges adjacent to dislocations so that the dislocations can sweep easily by hydrogen bond exchange. Recovery rates and grain boundary migration are also enhanced as the hydrolysis reduces barriers to the climb of dislocations (Green et al., 1970; Hobbs, 1968).

The transition from ductile to brittle behavior (because of the high pore pressure induced) during dehydration of serpentinite certainly provides a likely mechanism for the generation of shallow-focus earthquakes associated with Beniof zones (Raleigh and Paterson, 1965). Other dehydration reactions involving talc and amphibole $\left(\mathrm{H}_{2} \mathrm{O}\right.$ is released in the temperature interval $800^{\circ} \mathrm{C} t 01100^{\circ} \mathrm{C}$ ) extend the depth to which elastic strain energy may by released by fauting (Raleigh and Lee, 1969). A similar mechanical weakening during dehydration of gypsum, the abnormally high fluid pressures encountered during drilling evaporite sequences, and the common occurrence of gypsum/anhyarite at the sole of major thrust faults (Heard and Rubey, 1966) all provide support for the Hubbert-Rubey (1959) and Rubey-Hubbert (1959) hypothesis for the mechanics of overthrust fauting.

As a final example, it has been found recently (independently and nearly simultareously), in Griggs' (Post, 1970), Raleigh's (Raleigh and Kirby, 1970), and the writer's (Carter and Ave'Iallemant, 1970) laboratories, that steady state deforination of dunite and peridotite is governed by a pover law or the form $\dot{\varepsilon}=A o^{n} \exp (-Q / R r)$. For dunite deformed in the absence of externally released $\mathrm{H}_{2} \mathrm{O}$, empirical evaluations of the constant $\mathrm{A}\left(10^{8}-10^{10}\right)$, the stress exponent n (4-6), and the creep activation energy $Q(90$ to $120 \mathrm{Kcal} / \mathrm{mole}$ ) allow estimates to be made of. stresses and equivalent viscosities in the upper mantle. Depending on the reotherm chosen, the stresses at a strain rate of $10^{-14} / \mathrm{sec}$. range from about 1 to 100 bars in the depth interval 75 to $400 \mathrm{~km}$ and the viscosities range from $10^{20}$ to $10^{22}$ poise. The viscosity is minimum at about $200 \mathrm{~km}$ and increases slowly below that depth, in contrast to the very rapid increase calculated on the assumption linearly viscous behavior. These new observations require modifications 
to be made of theoretical attempts to model large-scale motions in the Earth's mantie.

\section{ACKNOWLEDSMENY'S}

The writer is indebted to Drs. H.G. Ave'Lalzemant, H.W. Green, C.B. Raleigh and, especially, O.B. James for critical comments and beneficial suggestions that resulted in a substantial improvement of this paper. This work was supported by National Science Foundation Grant GA-15412.

The publication was, in part, supported by NASA Contract No. NSR-09-05I-00I. 
Amelinckx, S., Etchpits and dislocations along grain boundaries, sliplines and polysonization walls, Acta. Metal., 2, 848-853, 1954.

Amelinckx, S. and R. Strumane, Geometry and kinetics of the polygonization of sodiun chloride, Acta. Metal., 8, 312-320, 1960.

Ave'Lallemant, H.G., Structural and petrofabric analysis of an "Alpine-type" peridotite: The Iherzolite of the French Pyrenees, Leidse Geol. Med, , 4,2, $1-57,1967$.

Ave'Lallemant, H.G. and N.L. Carter, Syntectonic recrystallization of olivine and modes of flow in the upper mantle, Geol. Soc. Amer. Bull., 81, 2203-2220, 1970. - Pressure dependence of quartz lamellac oxientations, in press, An. Jour. Sci., 1971.

Bäeta, R.D. and K.H.G. Ashbee, Siip systems in quartz: I. Experiments, Amex. Miner., $54,1551-1573,1969 \mathrm{a}$.

, Slip systems in quartz: II. Interpretations, Amer. Miner., 54, 15741582, $1969 \mathrm{~b}$.

- Mechanical deformation of quartz: I. Constant strain rate compression experiments, Phil. Mag., 22, 601-623, 1970a.

, Mechanical deformation of quartz: II. Stress relaxation and themal activation parameters, Phil. Mag., 22, 625-635, 1970b.

Baker, D.W., H.R. Wenk and J.M. Christie, X-ray analysis of preferred orientations in fine grained quartz aggregates, Jour. Geol., 77, 144-172, 1969.

Blacic, J.D., and D.T. Griggs, New Phenomena in experimental deformation of quartz at low strain rate, (Abs.), Amer. Geophys. Un., Trans., 46, 541, 1965.

Borg, I.Y. and J.W. Handin, Experimental deformation of crystalline rocks, Tectonophys., 3, 249-348, 1966.

Borg, I.Y. and H.C. Heard, Experimental deformation of plagioclases, in Experimental and Natural Rock Deformation, P. Paulitsch, Ea., Springer-Verlag press, New Yoxk, p. 375-403, 1970 .

Bunch, T.E., Some characteristics of selectud minerals from craters, ir shock Metamorphism of Natural Materials, B.M. French and N.M. Short, Eds., Kono Book Corp., Baltimore, Ma., 413-432, 1968.

Cahn, R.W., Slip and polygonization in aluminum, Jour. Inst. Metals, 79, 129-158, 1951. Carter, N.I., Experimental deformation and recrystallization of quartz, Ph. D. thesis, Univ. Calit., Ios Angeles, 214 p., 1963. - Basal quartz deformation lamellae - a criterion for recognition of impactites, Ancr. Jour. Sci., 263, 786-806, 1965. 
Carter, N.L., C.B. Raleigh and P.S. DeCarli; Deformation of olivine in stony meteorites, Jour. Geophys. Res., 73, 5439-5461, 1968.

Carter, N.L., Dynamic deformation of quartz; Shock metamorphism of natural materials B.M. French and N.M. Short, Eds., Mono Book Corp., Baltimore, Maryland, 453-474, 1968.

Carter, N.I., J.M. Christie and D.T. Griggs, Experimentally produced deformation lamellae and other structures in quartz sand, (Abs.), Jour. Geophys. Res., 66, 2518--2519, 1961.

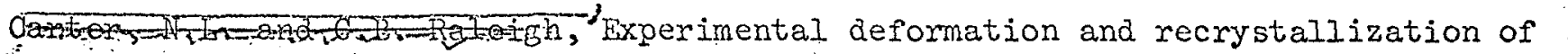
quartz, Jour. Geol., 72, 687-733, 1964.

Carter, N.L, and Melvin Friedman, Dynamic analysis of deforned quartz and calcite from the Dry Creek Ridge Anticline, Montana, Am. Jour. Sci., 263, 747-785, 1965.

Carter, N.L. and C.B. Raleigh, Principal stress directions from plastic flow in crystals, Geol. Soc. Amer. BuIl., 80, 1231-1264, 1969.

Carter, N.L. and H.G. Ave'Lallemant, High temperature flow of dunite and peridotite, Geol. Soc. Amer. Buil1., 81, 2181-2202, 1970.

Carter, N.L. and H.C. Heard, Temperature and rate-dependent deformation of halite, Amer. Jour. Sci., 269, 193-249, 1970.

Chao, E.C.T., Pressure and temperature histories of impact metamorphosed rocks - based on petrographic observations; in Shock Metamorphism of natural materials, B.M. French and N.M. Short, Eds., Mono Book Corp., Baltimore, Maryland, 35, 158, 1968 Christie, J.M. and C.B. Raleigh, The origin of deformation lamellae in quartz, Amer. Jour. Sci., 257, 385-407, 1959.

Christie, J.M., D.T. Griggs and N.L Carter, Experimental evidence of basal slip in quartz, Jour. Geol., 72, 734-756, 1964.

Christie, J.M. and H.W. Green, Several new slip systems in quartz, (Abs.), Amer. Geophys. Un. Trans., 45, 103, 1964.

Christie, J.M., J.A. Tullis and J.D. Blacic, The non-rational nature of deformation lamellae in quartz (Abs.), Am. Geophys. Un. Trans., 49, 314, 1968.

Clark, S.P. Ir. and A.E. Ringwood, Density distribution and constitution of the mantle, Rev. Geophys., 2, 35, 1964.

Coe, R.S., The thermodynamic effect of shear stress on the ortho-clino inversion in enstatite, and other coherent phase transitions characterized by finite simple shear, Contr. Mineral. and Petrol., 26, 247-264, 1970.

Collee', A.I.G., A fabric study of therzolites with special reference to ultrabasic nodular inclusions in the lavas of Auvergne (France), Leids, Geol. Med., 28, $1-102,1962$.

den Tex, E., Origin of ultramafic rocks, their tectonic setting and history, Tectonophysics, 7, 457-488, 1969. 
Engelharat, W.V., F. Hörz, D. Stốrlen and W. Bertsch, Observations on quartz defomation in the breccias of West Clearwater Lake, Canada and the Ries Basin, Germany; in Shock Metamorphism of Natural Materials, B.M. French and N.M. Short, Eds., Mono Book Corp., Baltimore, Ma., 475-482, 1968.

Fairbairn, H.W., Structural petrolocy of deformed rocks, 2nd. Ed., Addison-Wesley Pub. Co., Cambridge, Mass., 334 p., 1949.

Green, H.W., Extreme preferred orientation preduced by annealing, Science, 157 , $1444-1447,1967$.

Green, H.W., D.I. Griggs and J.M. Christie, Syntectonic and annealing recrystallization of fine-grained quartz aggregates, in Experimental and Natural Rock Deformation, P. Paulitsch, Ea., Springer-Verlag Press, New York, p. 272-335.

Griggs, D.T., Hydrolytic veakening of quartz and other silicates, Geophys. Jour. Roy. Astr. Soc., 24, 19-31, 1967.

Griggs, D.T. and J.D. Blacic, The strength of quartz in the ductile regime (Abs.), Am. Geophys. Un Trans., 45, 102-103, 1964.

- Quartz: anomalous weakness of synthetic crystals, Science, 147, 292-295, 1965. Griggs, D.T., F.J. Turner and H.C. Heard, Deformation of rocks at $500^{\circ} \mathrm{C}$ to $800^{\circ} \mathrm{C}$ : in Rock Defomation, D.T. Griggs and J.W. Handin, Eds., Geol. Soc. Amer. Mem., 79, $39-104,1960$.

Hartman, P. and E. den Tex, Piezocrystaline fabrics of olivine in theory and nature, 22nd. Inter. Geol. Cong., New Delhi, Sect. Rock Deformation.Tectonophysics, 1964. Heard, H.C., The effect of large changes in strain rate in the experimental deformation in rocks, Ph.D. dissert., Univ. Calif., Los Angeles, 202 p. 1962. , Steady-state flow in Yule Marble at 500-800 C, (Abs.), Am. Geophys. Un. Trans., 49, 312, 1968.

Heard, H.C. and W.W. Rubey, Tectonic Implications of Gypsum dehyarations, Geol. Soc. Am. Bull., 77, 741-760, 2966.

Heard, H.C. and N.L. Carter, Experimentally induced "Natural" intragranular Plow in quartz and quartzite, Amer. Jour. Sci., 266, 1-42, 1968.

Helmstaedt, H., and O.L. Anderson, Petrofabrics of mafic and ultramafic inclusions from kimberlite pipes in southeastern Utah and northeastern Arizona, (Abs.), Amer. Geophys. Un. Trans., 50, 345, 1969.

hobos, B.T., Recrystallization of single crystals of quartz, Tectonophysics, 6 , $353-401,1968$.

Hörz, F., Statistical measurements of deformation structures and refractive indices in experimentally shock-loaded quartz; in Shock Metamorphism of Matural Matexials B.M. French anả H.M. Short, Eas., Mono Book Corp., Baltinore, Ma., 243-254, 1968. James, O.B., Shock ana thexmal metarnorphism of basalt by nuclear explosion, Nevada Test Site, Science, $166,1615-1620,2969$. 
Kunazawa, M., The elastic constants of single crystal orthopyroxene, Jour. Geophys. Res., 74, 5973-5980, 1969.

Laves, F., Mechanische zwillingsbildung in Feldspaten in Abhangigkeit von ordnungunoranung der Si/AI - Verteilung Immerhalf des $\left(S i, A_{4}{ }_{8}\right)$ - Gerustes, Naturwissenschaften, $39,546-547,1062$

McLaren, A.C., J.A. Retchford, D.T. Griggs and J.M. Christie, Transmission electron microscope study of brazil twins and dislocations experimentally producea in natural quartz, Phys. Stal. Sol., 19, 631-644, 1967.

McLaren, A.C. and J.A. Retchfora, 'Iransmission electron microscope study of the dislocations in plastically deformed synthetic quartz, Phys. Stal. Sol. , 33, $657-668,1969$.

Móckel, J.R., Structural petrology of the garnet peridotite of Alpe Arami (Nicino Switzerland), Leidse Geol. Med., 42, 61-130, 1969.

Mugge, 0. , and F. Heide, Einfache schiebungen am anorthit, Neÿes Jahr. Mineral.

Abh. I, 64, 163-170, 1931.
$\mathcal{L}$. Hubbert, M.K. and W.W. Rubey, Role of fluid pressure in mechanics of overthrust faulting: I, Mechanics of fluid-filled porous solids and its application to overthrust faulting, Geol. Soc. Amer. Bull., 70, 115-166, 1959.

O'Hara, M.H., Mineral parageneses in ultrabasic rocks: In UJtramafic and related rocks, P.J. Wiley, Ed., John Wiley and Sons, New York, 393, 1967.

Packer, C.M. and O.D. Sherby, Interpretation of superplasticity phenomenon in two phase alloys, Amer. Soc. Metals Trans., 60, 21, 1967.

Post, R.M., Jr., The flow laws of Mt. Burnet dunite at $750^{\circ}-1150^{\circ} \mathrm{C}$, (Abs.), Amer. Geophys. Un. Trans., 51, 424, 1970.

Raleigh, C.B., Fabrics of naturally and experimentally deformed olivine, Ph.D. dissert., Univ. Calif., Los Angeles, 214 p. 1963.

Raleigh, C.B., Glide mechanisms in experimentally deformed minerals, Science, 150, $739-741,1965$.

- Crystallization and recrystallization of quartz in a simple pistoncylinder device, Jour. Geol., 73, 369-377, 1965a.

- Plastic deformation of upper mantle silicate minerals, Royal Astr. Soc. Geophys. Jour. , 4, 45, 1967.

, Mechanisms of plastic deformation of olivine, Jour. Geophys. Res., 73, 5391, 1968.

Raleigh, C.B. and J.I. Talbot, Mechanical twinning in naturally and experimentally deformed diopside, Amer. Jour. Sci., 265, 151-165, 1967.

Raleigh, C.B. and W.H.K. Lee, Sea-floor spreading and island arc tectonics, state of Oregon Buzz., 65, 99-110, 1969. 
Raleigh, C.B. and S.H. Kirby, Creep in the upper mantle, Mineral. Soc. Aner. Spec.

Pap. , 3, 113-121, 1970.

Paleigh, C.B., S.H. Kirby, N.L. Carter and H.G. Ave'Lallemant, Slip and the clinoenstatite transfomation as competing rate processess in enstatite, in press, Jour. Geophys, Res., 1971.

Riecker, R.E. and T.P. Rooney, Deformation and polymorphism of enstatite under shear stress, Geol. Soc. Amer. Bull., 78, 1045-1054, 1967.

Robertson, P.B., M.R. Dence anà M.A. Vos, Deformation of rock-foming minerals from Canadian Craters; in Shock Metamorphism $\dot{P}$ of Natural Materials, B.M. French and N.M. Short, Eas., Mono Book Corp., Baltinore, Ma., 433-452, 1968.

Rubey, W.W. and M.K. Hubbert, Role of fluid pressure in nechanics of overthrust fanlting:

II. Overthrust belt in geosynciinal area of Western Wyoming in light of fluidpressure hypothesis, Geol. Soc. Amer. Bull., 70, 167-206, 1959.

Sander, B., Gefügekunde der gesteine, Springer, Berlin, Vienna, 352 p., 1930.

Schnidt, W., Gefugestatistik, Tschemaks mineralog, petrog, Mitt., 38, 395-423, 1925.

"Seifert, K.W., Deformation banas in albite, Amer. Mineral., 50, 1469-1472, 1965.

Strength of Aairondack anorthosite at elevated temperatures and pressures,

Geol. Soc. Amer., 80, 2053-2060, 1969.

[Sclar, C.B., Shock metamorphism of lunar rocks and fines from Tranquillity Base, in

Proceedings of the Apollo 11 Lunar Science Conference, A.A. Levinson, Ea.,

Pergamon, 849-86́4, 1970.

Sherby, O.D. and P.M. Burke, Mechanical behavior of crystalline solids at elevated

temperature, Prog. in Matr. Sci., 13, 325-390, 1968.

Starkey, J. and W.L. Brown, Kunstlicher erzeugang mechanischer zwillinge in Anorthit.

Zeitschr Kristal., 120, 388-392, 1964.

Sylvester, A.G. and J.M. Christie, The origin of crossed girdle orientations of optic

axes in deformed quartzites, Jour. Geol., 76, 571-580, 1968.

Trommsdorf, V. and H.R. Wenk, Terrestrial metamorphic clinoenstatite in kinjs of

bronzite crystals, Contr. Mineral. Petrol., 19, 158-168, 1968.

Tullis, J.A., Preferred orientation in experimental quartz mylonites, (Abs.), Amer.

Geophys. Un. Trans., 49, 755, 1968.

- Preferred orientation in rocks produced by Dauphine' twinning, Science, $168,1342-1344,1970$.

Turner, F.J., Preferred orientation of olivine crystals in peridotites with special reference to New Zealand examples, Roy. Soc. New Zealand Trans., 72, 280-300, 1942. Turner, F.J., D.T. Griggs and H.C. Heard, Bxperimental deformation of calcite crystals, Geol. Soc. Amer. Bul1., 65, 883-934, 1954. 
Turnex, F.J., H.C. Heard and D.T. Griges, Experimental deformation of enstatite and accompanying inversion to clinoenstatite, Intern. Geol. Cong., 21, Part I8, $399-1,08,1960$.

Weertman, J., Dislocation climb theory of steady state creep, Aner. Soc. Metals. Trans., 61, 681, 1968.

, The creep strength of the Earth's mantle, Rev. Geophys., 8, 145-169, 2970. 
1. Microstructures induced by plastic deformation. Scale lines are in millineters. A. Deformation lanellae (N-S Iinear features) in Orocopio quartzite; phase contrast illumination. Note sharp asymetric nature of lameliae.

$B, C$. Deformation lanellae ( $N$-W-trending linear features) in bright field (B) and phase contrast (C) in experimentally deformed crystal. The lameliae are normal to a zone of undulatory extinction.

D. Kink bands ( $N-S$ bands) parallel to (100) in naturally deformed olivine.

E. Deformation lamellae (N-S Iinear features) normal to zones of unculatory extinction in experimentally deformed olivine.

F. Decorated lamellae (N-E-trending linear features) consisting of particles of Mg which have diffused along dislocation lines in (010) plane during experiment.

2. Orientations of quartz deformation lamellae produced experimentally in canyon Creek quartzite at a constant strain rate of $7.8 \times 10^{-6}$ sec. $^{-1}$ as functions of temperature and pressure (Ave'Lallemant and Carter (1968).

3. Histograms showing the angle between the c-axis and poles to lamellae proviaing the basis for subaivision into the various lamellae fields of Figure the subbasal I lamellae orientations (a; combined results of Heard and Carter, 1968 and Ave'Lallemant and Carter, 1971) are most nearly similar to those of natural lameliae ( $f$; Carter and Friednan, 1965).

4. Orientations of various subfabric elements in experimentally ( $a, b, c$; Heard and Carter, 1968) and naturally (d,e,f; Carter and Friedman, 1.965) deformed quartzite (Carter and Raleigh, 1969). N-S arrows in a,b,c show orientation of $\sigma_{1}\left(\sigma_{2}=\sigma_{3}\right)$ and dashed small circles are at $45^{\circ}$ to $\sigma_{1}$. Dashed lines and circles in e and $I^{\circ}$ show stress orientations deduced from calcite twins. Lower hemisphere, equal area projections.

A,D. Poles to 128 sets of lamellae in experimentally deformed specimen; contours at $7,5,3,1$ percent per 1 percent area (A). Poles to 89 sets of lamellae in naturally deformed quartzite; fontours at $6.7,4.5,2.2$ and 1.1 percent per 1 percent area (D).

$B, E$. -axes in more (solid circles; $\underline{c}_{1}$ ) and less (open circles; $\underline{c}_{0}$ ) defomed parts of individual grains.

$C, F$. Poles to lamellae (points of arrows) and $c$-axes (enas of arrows) in grains containing lamellae. 
5. Ihree-dimensional diagran showing quartz lamelace orientations in $\mathrm{T}-\mathrm{p}-\dot{\varepsilon}$ space and extrapolated to lower rates expected of natural deformations (Ave'Lallemant and Carter, 1971). T-E results are from Heard and Carter (1968) and P-T results are from Ave'Lallemant and Carter (1971). The possible continental geothem is from Clark and Ringwood (1964).

6. Poles to slip planes detemined from external rotations in kink banas of naturally deformed olivine (Raleigh and Kirby, 1970). The slip system is \{0kI\}[100].

7. Slip systems in experimentally deformed olivine aggregates as functions of temperature and strain rate as deduced from lamellae orientations and external rotations (Carter and Ave'Lallemant, 1970).

8. Three-dimensional diagram showing variations in slip systens in olivine in $P-T-\dot{\varepsilon}$ space constructed from data of Carter and Ave'Lallemant (1970) and. extrapolated to higher pressures and lower strain rates. The oceanic geotherm is from Clark and Ringwood (1964).

9. Microstructures induced by plastic deformation. Scale lines are in the milimeters. A. Naturaliy deformed enstatite kinked on $\{100\}[001]$; (100) exsolution lamellae are nomal to kink boundaries.

B. Experimentally kinked enstatite. Light bands have transformed to clinoenstatite as have light lamellae in dark enstatite bands (photo courtesy of S.H. Kirby).

C. Thin, light $\mathbb{N}-\mathrm{S}$ trending bands are $\{100\}$ twin bands in diopside.

D. Kink bands in naturally deformea plagioclase produced by slip on $\{010\}$ (Seifert, 1965).

10. Temperatures and strain rates at which enstatite transforms to clinoenstatite and at which the enstatite deforms by kinking due to slip on \{100\}[001] and polygonizes (Raleigh et al., 1971). The dashed boundary is that estimated for 1/8" samples for which the temperature distribution is less well known by comparison with $1 / 4$ " samples (solid lines).

11. Extrapclation to lower strain rates of boundary separating enstatite transformation vs. slip fields. The dashed line is the predicted boundary based on measurements of the flow law parameters for each process, projected in $\mathrm{I}-\dot{\varepsilon}$ space (Raleigh et al., 1971). 
13. Projection nomal to [010] of the diopside structure showing the twiming elenents (Raleigh and Talbot, 1967).

13. Sketch of the polygonization process.

A. Eage dislocations of like sign are created by bending.

B. The dislocations have climbed vertically and have formed walls nomal to their Burgers vectors. Few dislocations remain between walls and hence slip plane straightens.

C. An irregular wall formed by interaction of tivo mutualiy perpenaicular walls (Amelinckx and Strumane, 1960).

D. Distortion of crystal structure of dislocation walls and relation between spacing ( $h$ ) and misorientation $(0)$; $b$ is the Burgers vector (Read, 2953 ).

15. Photomicrôgraphs of recovery and recrystallization: Scale lines are in millineters. $A, B$. Polygonization in naturally deformea olivine in xenolith from Lunar Crater (A) anā olivine experimentally deformed at $950^{\circ} \mathrm{C}, \dot{\varepsilon}=10^{-6} / \mathrm{sec}$, and a constant stress of $9.5 \mathrm{~kb}$ (Raleigh and $\mathrm{Kirby}, 1970$ ). Indiviaual polygons are disoriented by less than $5^{\circ}$ and are nearly rectangular with edges parallel to (100) and (001).

c. Intragranular and grain boundary recrystallization in experimentally deformed dunite (Ave'Lallemant and Carter, 1970).

D. Total recrystallization of experimentally deformed dunite forming a new rock with strain free grains (Ave'Lallemant and Carter, 1970). Note general. elongation of grains in $N$-S direction, normal to $\sigma_{1}$.

E. Recrystalized pellet of ground $(<37 \mu$ ) dunite powder (Ave'Lallemant and Carter, 1970). Original grainsize is seen near East and West ends of specimen. Note flattening of grains normal to $\sigma_{1}$ which was oriented $E-W$.

F. Experimentally produced "mylonite" in highly compressed $(h-5)$ (Carter et al., 1964).

16. Diagram showing relation between polygon diameter $(L)$ and $\mu / \sigma$ in olivine for specinens deformed at a constant stress of $9.5 \mathrm{~kb}(\mathrm{~N}-27$ ) and $4.6 \mathrm{~kb}$ ( $\mathrm{N}-4 \mathrm{I}$ ) (Raleigh and Kirby, 1970). The larger sizes of polygons of naturally polygonized olivine in xenoliths from Hawai and Lunar Crater lead to the stress estimates shown in the upper part of aiagram.

17. Optically determined c-axis fabrics of syntectonically recrystallized quartz aggregates (A-D; Green et al., 1970), cold-worked and annealed bicrystal (E; Green et al., 1970) and cold-worked and annealed single crystal ( $P$; Hobbs, 1968). $\sigma_{1}$ is oriented $\mathrm{N}-\mathrm{S}$ in all diagrams. Lower hemisphere, equal area projections. 
17. A. e-axes in 516 grains recrystallized in $\alpha$-stability fiela in $r \| \sigma_{2}$ subriela (see $\mathrm{Pig}$. 18). Contours: 4,3,2,I percent per one percent area.

B. c-axes in 597 grains recrystalized in a-stability field in $r$ / $\sigma_{1}$ subrield (Fig. 18). Crossed-girdle fabric with $\varepsilon_{2}$ i io 2 intersection of girdies.

Contours: $2.5,2,1$ percent per one percent area.

c. - -axes in 500 grains recrystallized in the B-stability field shoving $\subseteq \| \sigma_{1}$ fabric. Contours: $4,2,1$ percent per one percent area.

D. c-axes in 300 grains recrystallized in the $\beta$-stability field showing composite $\subseteq \| \sigma_{1}$ and $\subseteq L \sigma_{1}$ fabric. Contours: 6,4,2,1 percent per one percent axea.

E. c-axes in 100 grains recrystallized along interface between crystals compressed parallel to $c$ (open square) and at $45^{\circ}$ to $c$ (solid square). The crystals were cold-worked and then annealed in the B-stability field. Contours: 5,3,1 percent per one percent area.

F. Natural crystal compressed i $r\{10 \bar{I} 1\}$ (c-axis indicated by solid square) at $520^{\circ} \mathrm{C}$ and then annealed at $1280^{\circ} \mathrm{C}$. c-axes in 210 new grains. Contours: 13,9,5,1 percent per one percent area.

18. Types of c-axis fabric observed by syntectonic recrystallization in $\alpha$-stability field as functions of temperature and strain rate (Green et al., 1970).

18. Fabrics of naturally $(A, B)$ and experimentally $(B, D, E)$ recrystallized olivine $(A, C, D)$ and enstatite $(B, E)$ : Great circies in $A, B$ show orientation of foliation. $\sigma_{I}$ is oriented $N-S$ in $C, D, E$ with a mineral flattening foliation parallel to $\sigma_{2}-\sigma_{3}$ plane $(E-W)$. Lower hemisphere, equal area projections; $\sigma_{1}$

A. 200 sets of principal indicatrix axes of olivine from Iherzolite in Pyrenees (Ave'Lallemant, 1967). Contours-at-intervals-of-one-percent-pen-one-pencent-area.

B. 100 sets of principal indicatrix axes of enstatite in same specimen as A. Contours at intervals-of-one-percent-per-one-percent area.

C. 200 set,s of principal indicatrix axes of olivine in Mt. Burnet specimen (Fig. I5D) totally recrystallized syntectonically at $1100^{\circ} \mathrm{C}, 15 \mathrm{~kb}, 10^{-6} / \mathrm{sec}$. in presence of $\mathrm{H}_{2} \mathrm{O}$ (Ave'Lallemant and Carter, 1970): Contours-at-intenvalsof-one-pereent-per-one-percent-area.

D. 350 sets of principal indicatrix axes of olivine in powder syntectonically recrystalizized at $1100^{\circ} \mathrm{C}, 13 \mathrm{~kb}, 7.8 \times 10^{-7} / \mathrm{sec}$. (Ave'Lallemant and Carter, 1970). Contours-at-intervals-of-one-percent-permone-percent-area"

I. 250 sets of principal indicatrix axes of enstatite in powder syntectonically recrystalized at $1000^{\circ} \mathrm{C}, 15 \mathrm{~kb}, 7.8 \times 10^{-7} / \mathrm{sec}$. Contouxs-at-intervalsmos? ane percent-per-one-percent-area. 
19

20. The P-I conditions of experimental syntectonic recrystallization experiments on olivine including relative grain growth (Ave'Lallemant and Carter, 1970) and equilibration fields of various ultramafic suites and peridotite solidus (O'Hara, 1967 ). 

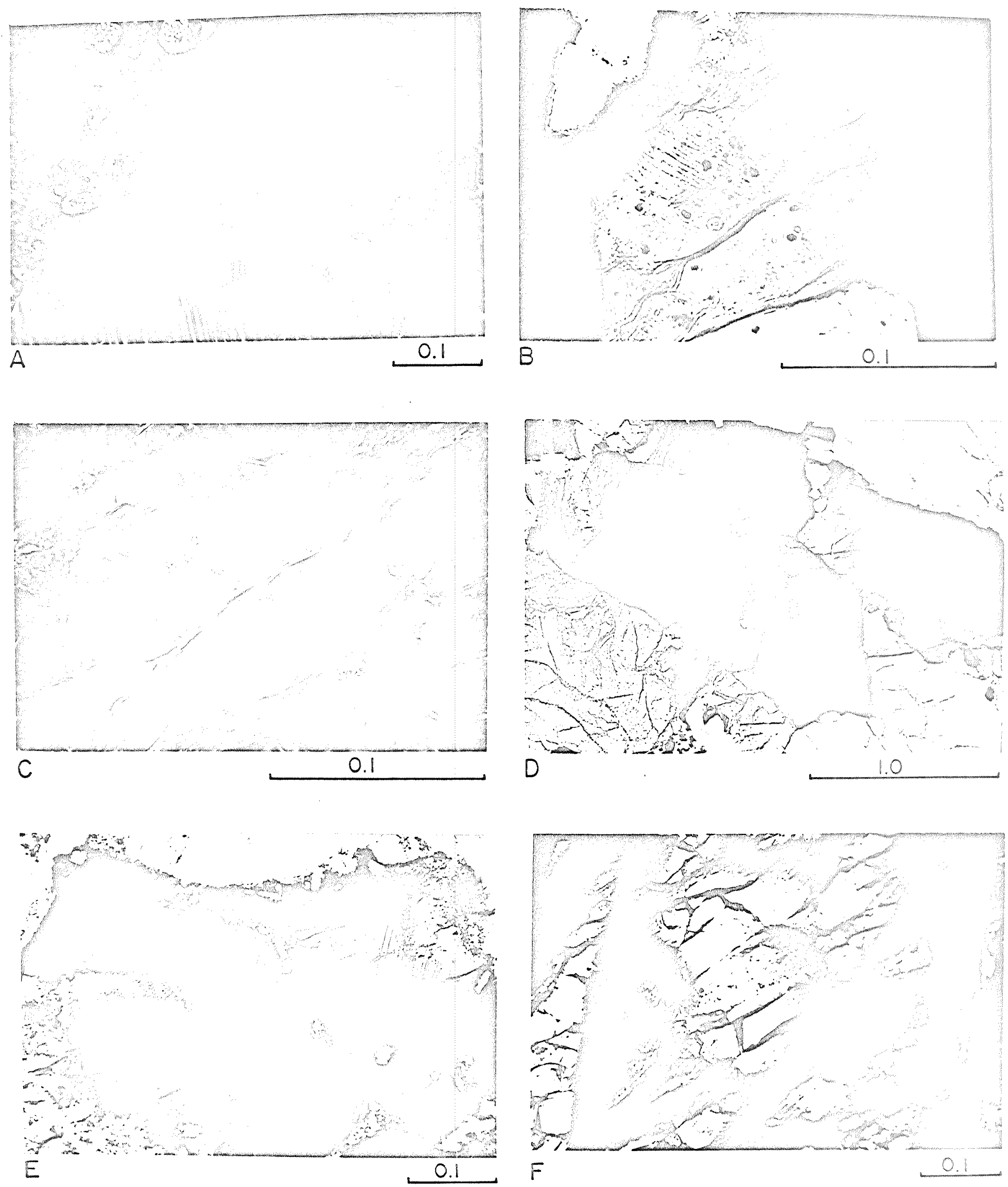


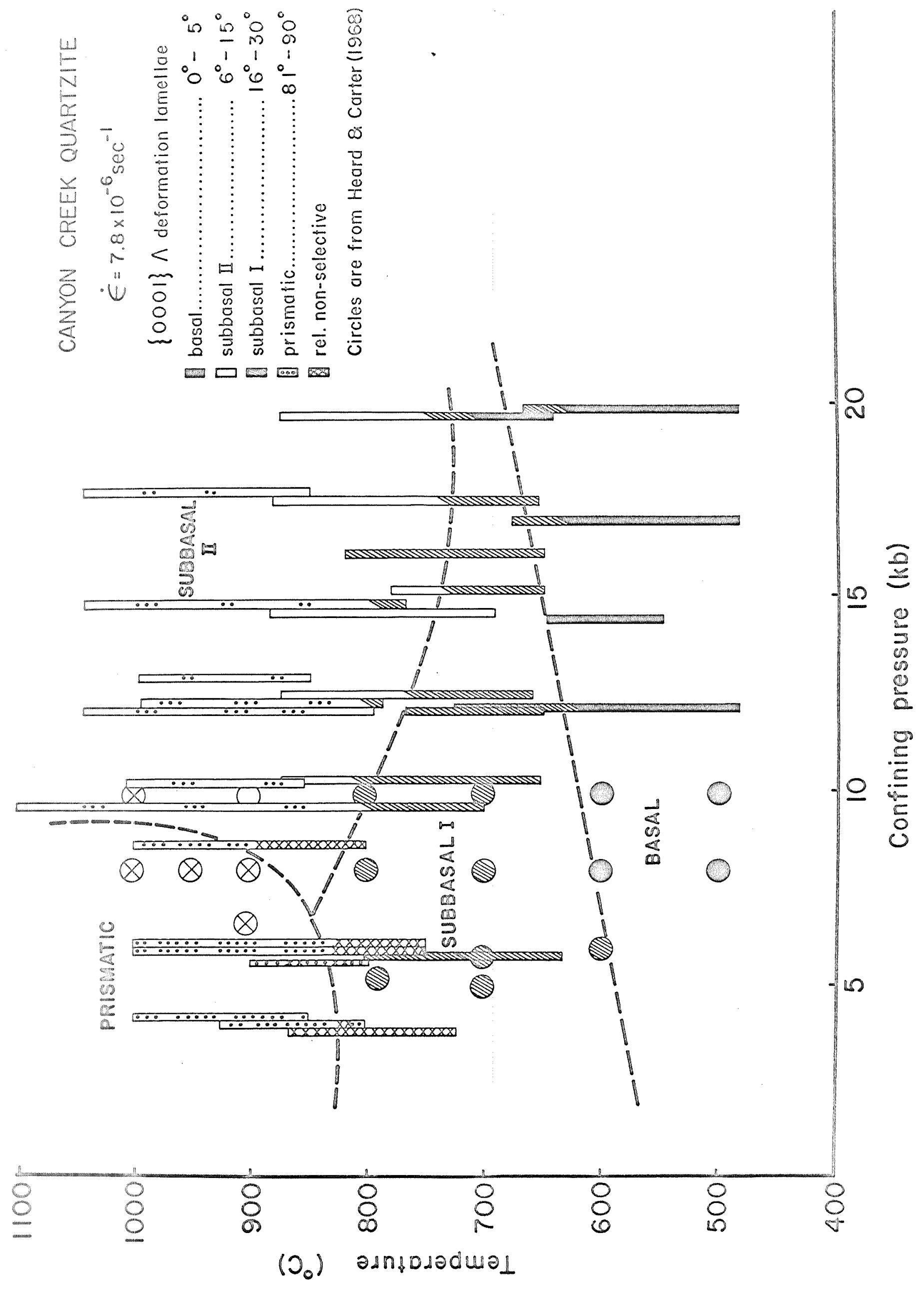




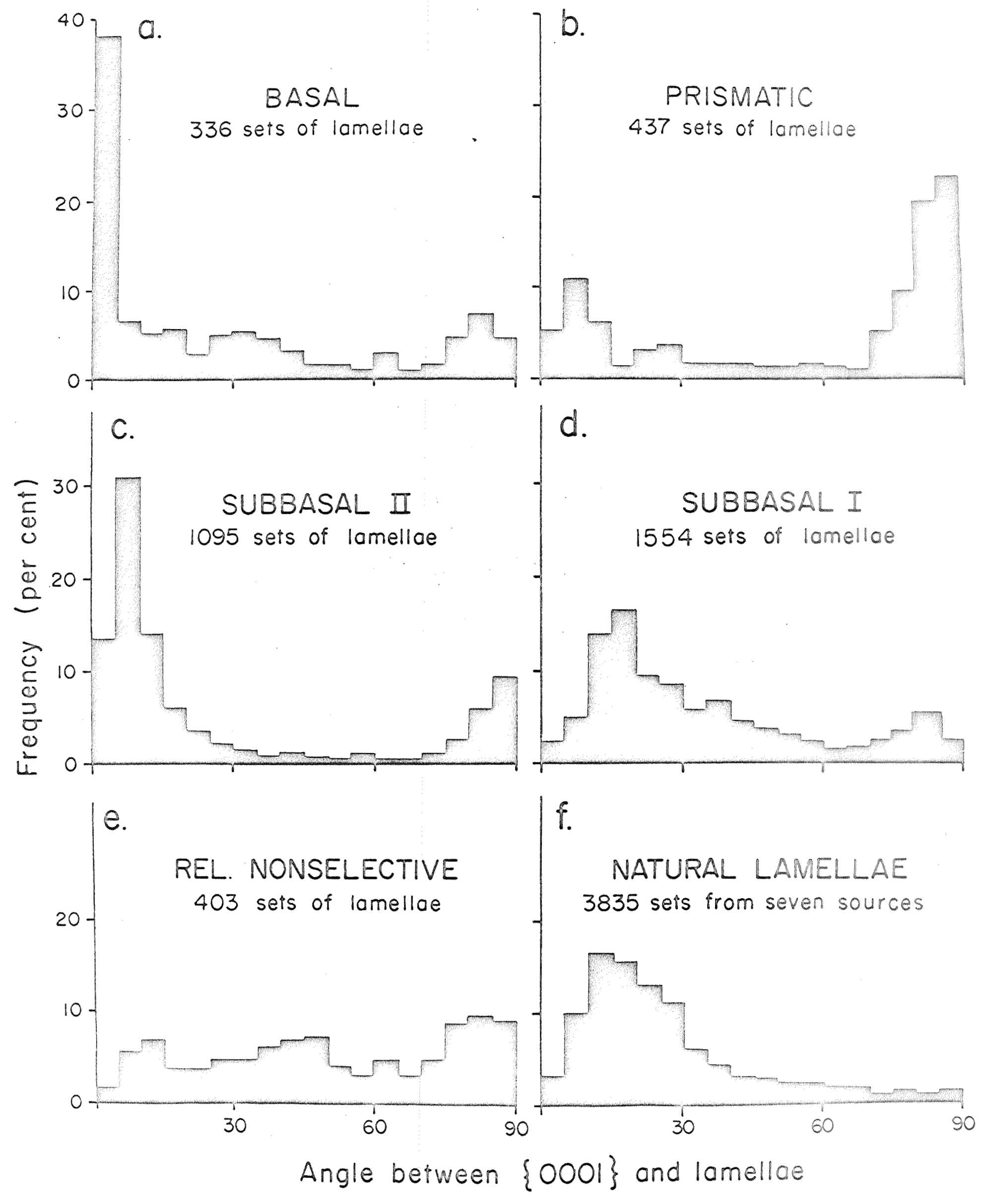



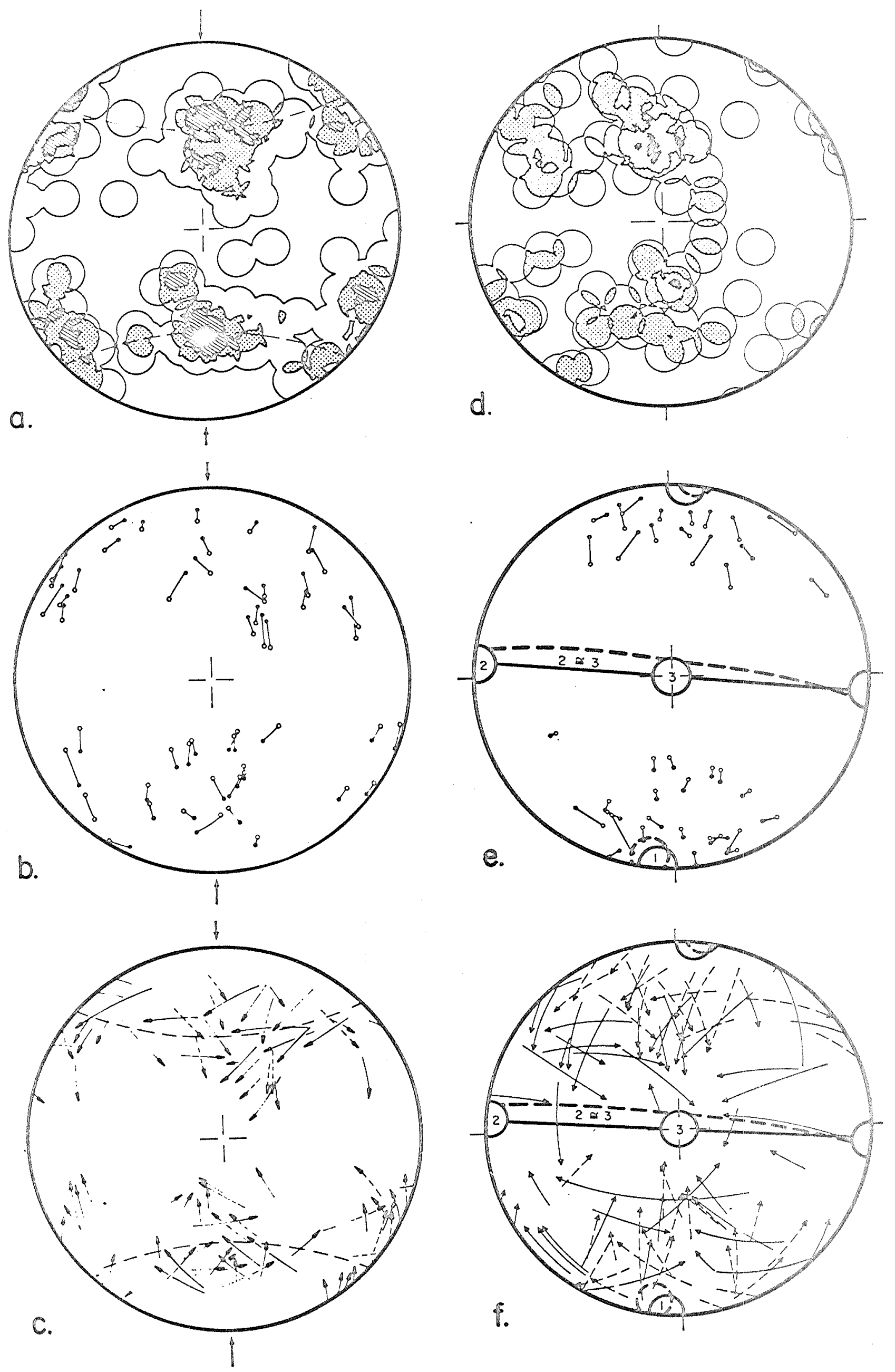


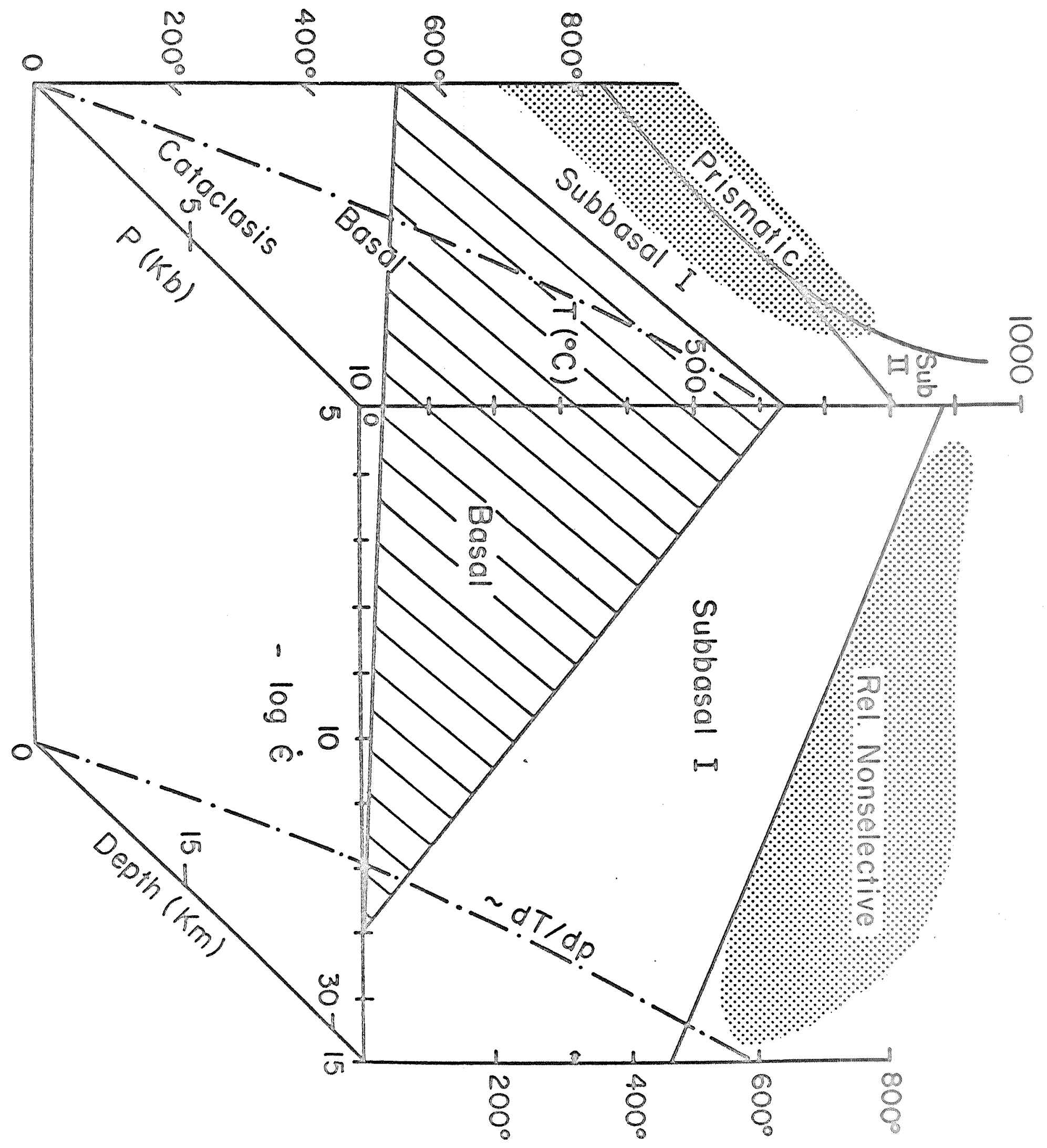



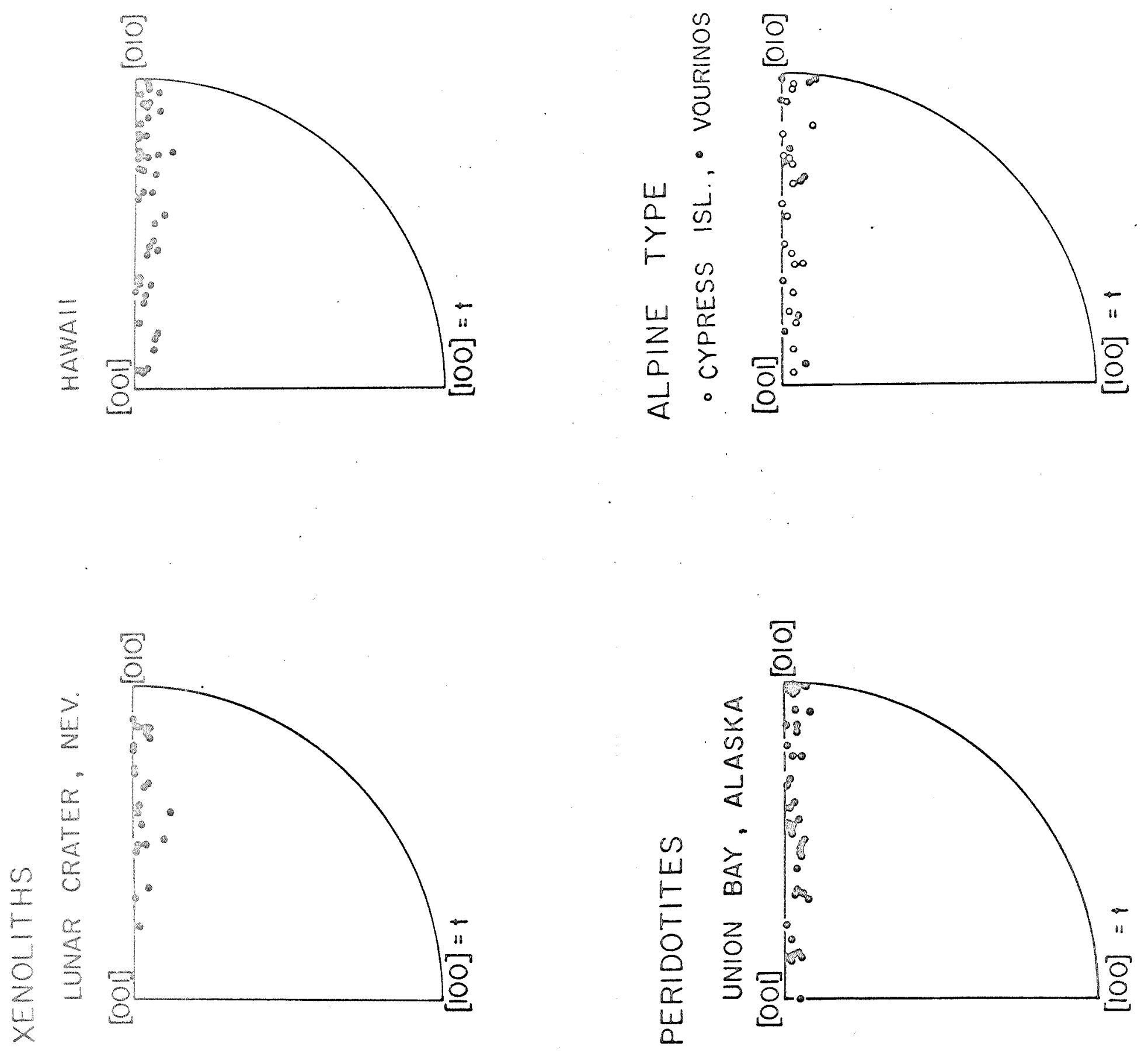


\section{PREDOMINANT SLIP MECHANISMS IN OLIVINE CONFINING PRESSURE $\sim 15 \mathrm{~K}: \mathrm{b}$}

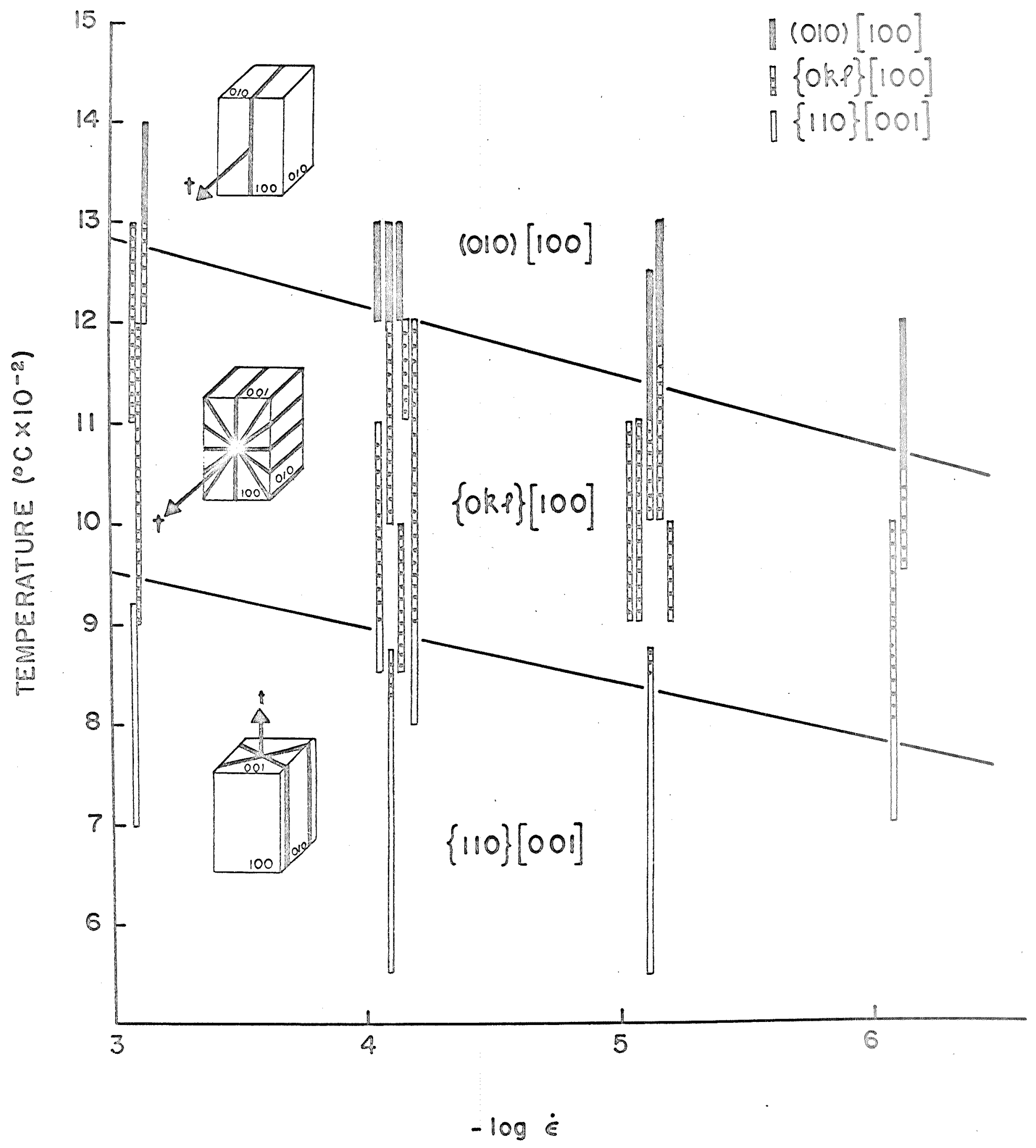




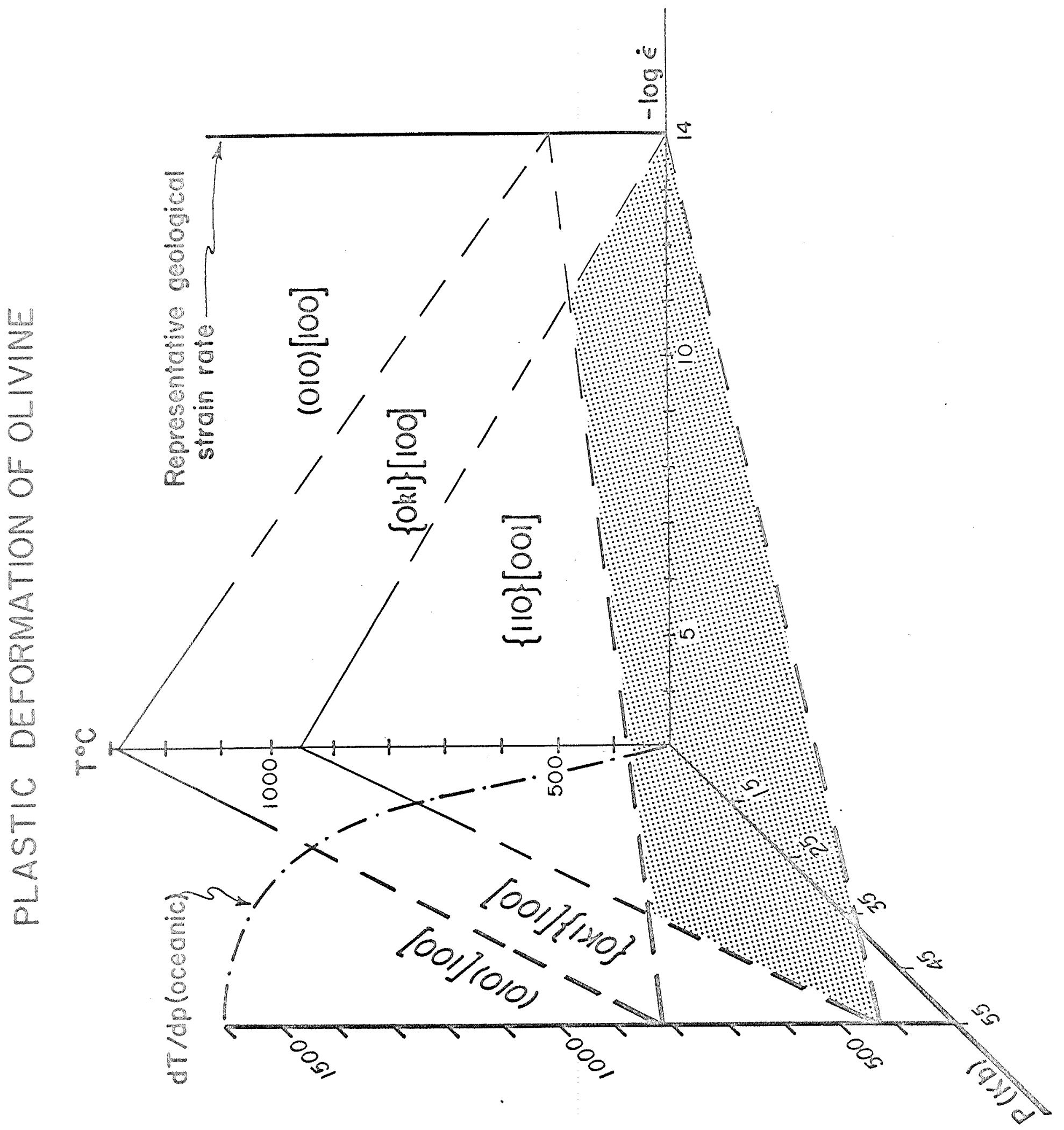



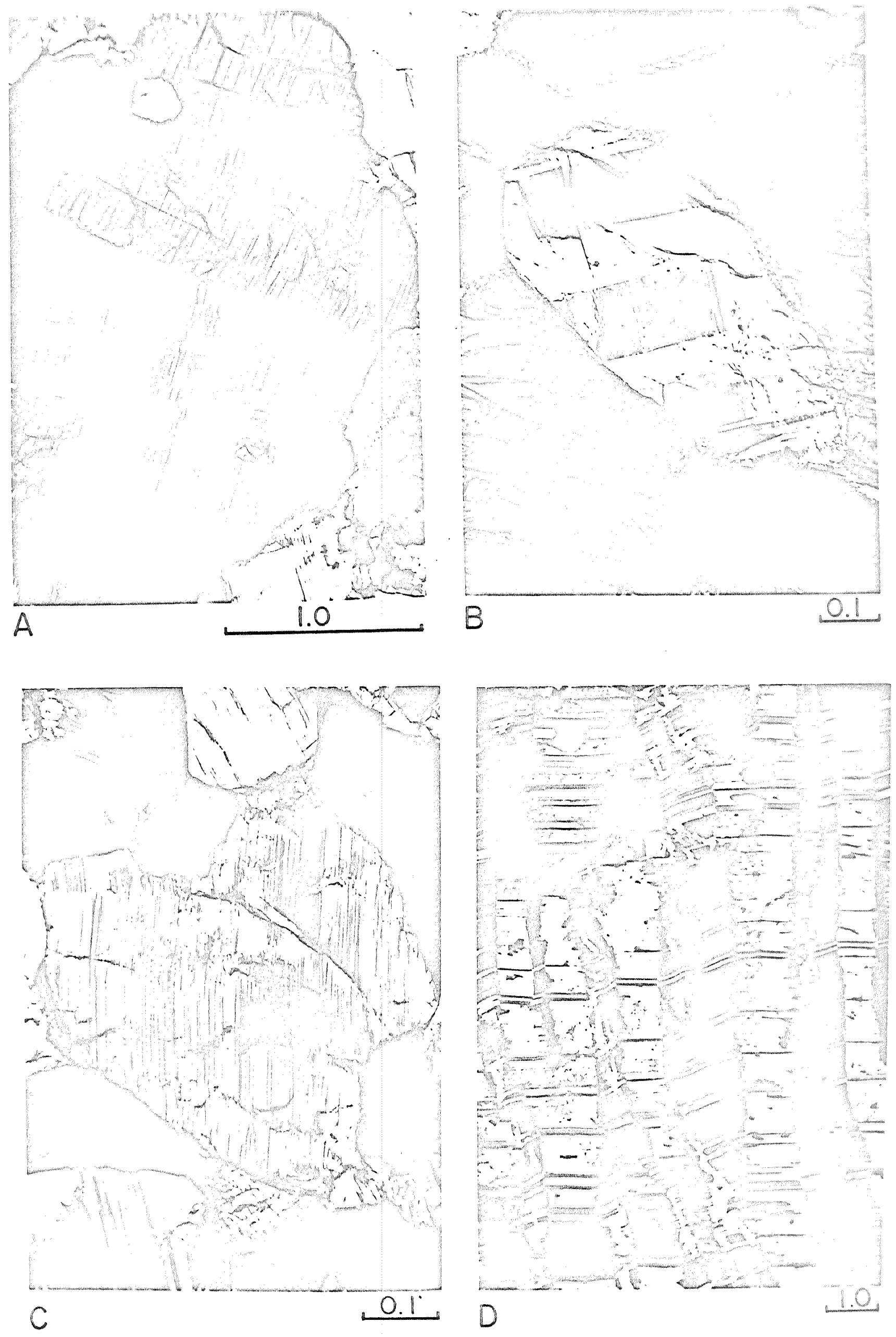

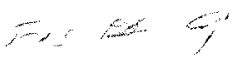




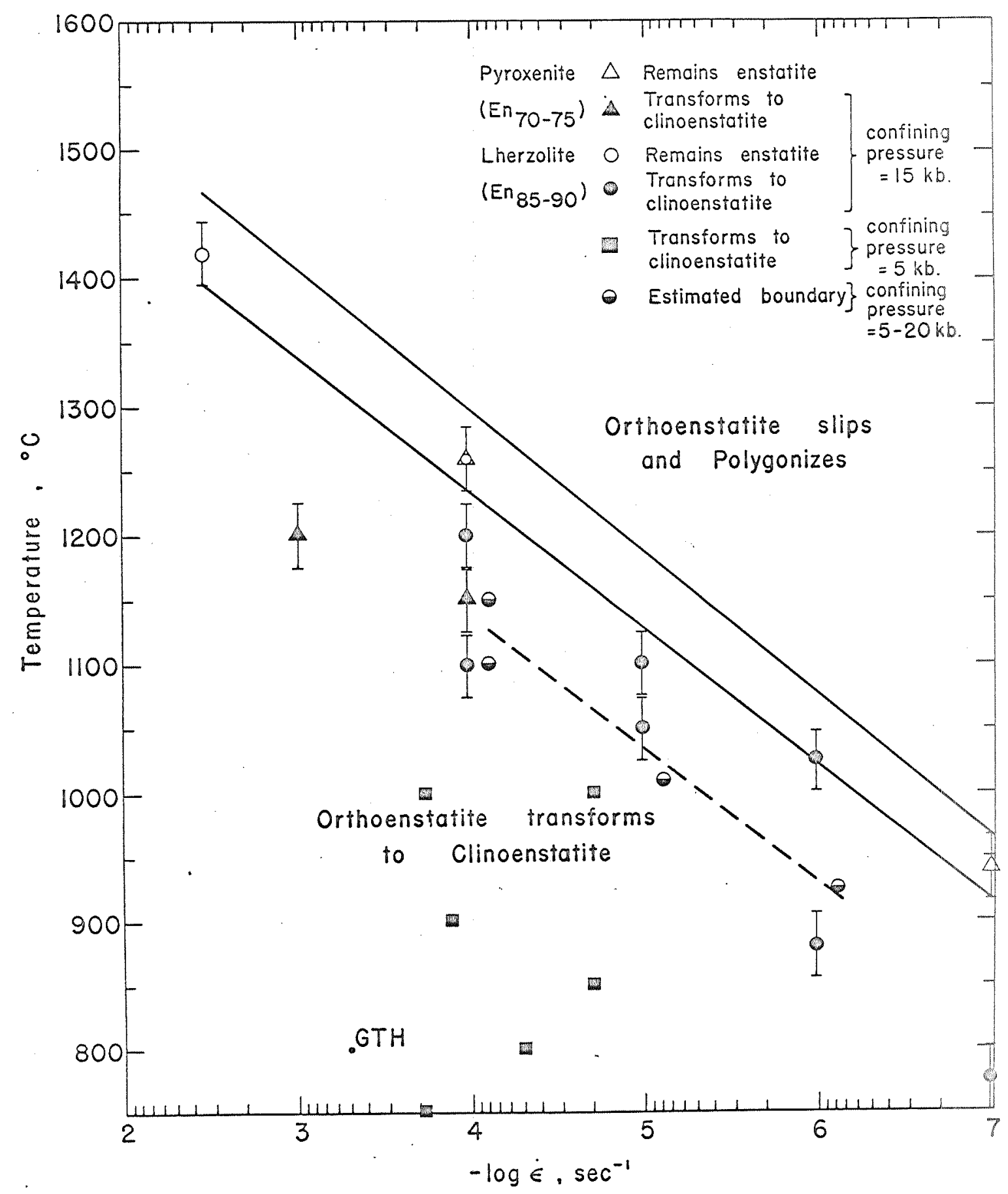

$=0+y 0-y$ y 


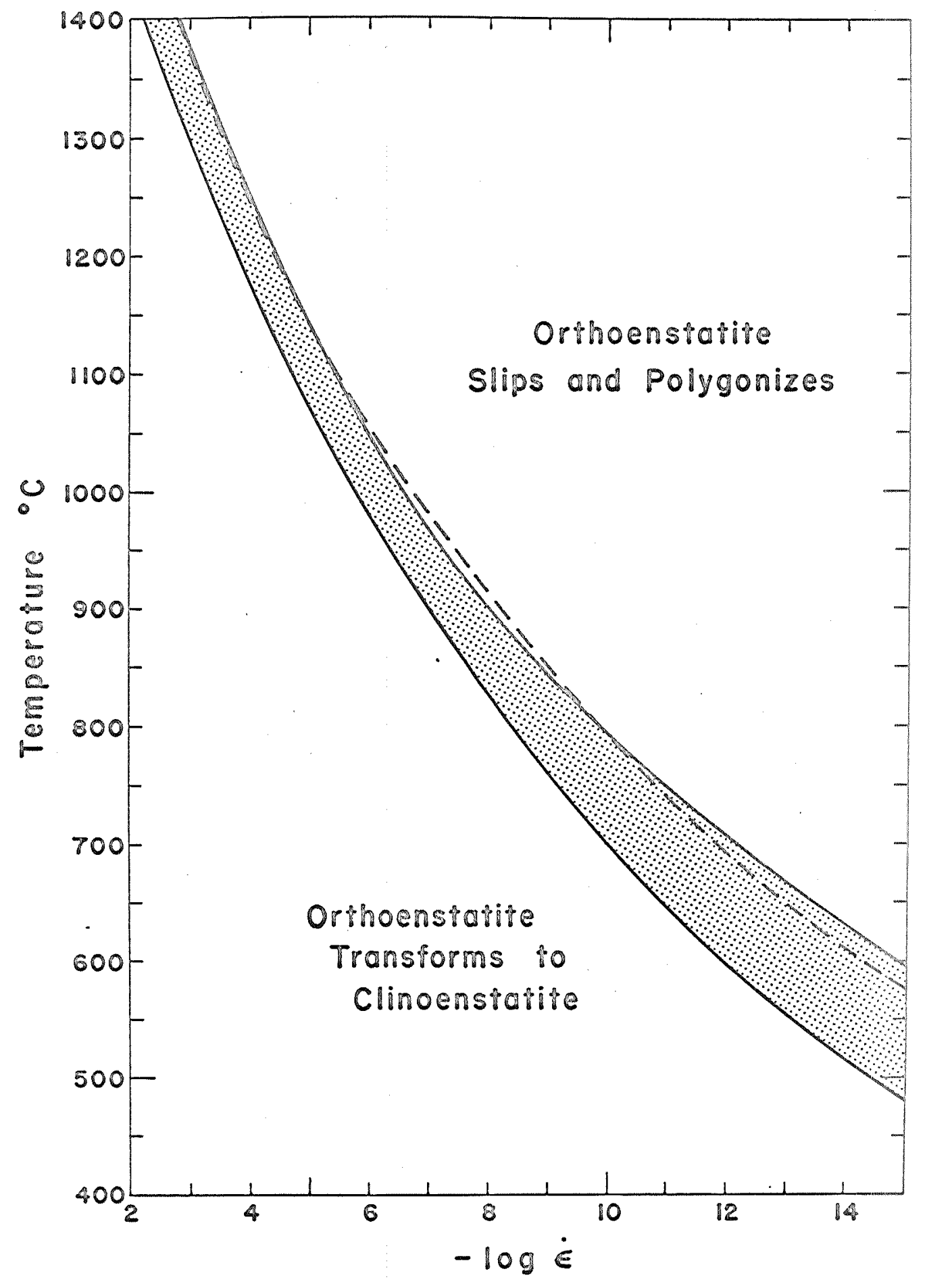




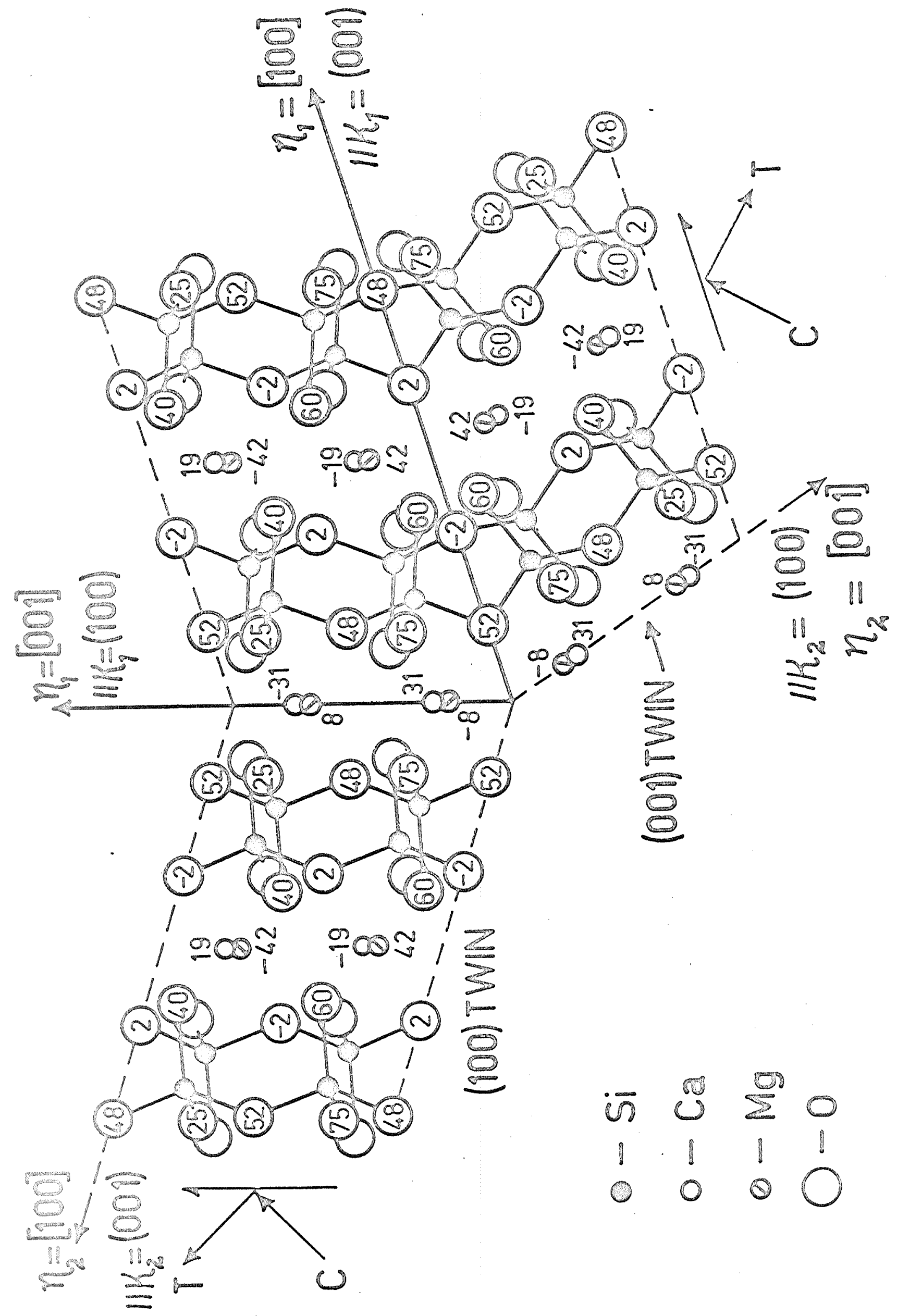


$\sqrt{\frac{3+2+1+1+21}{1+2+1+1+1+2}}$ $+2+2+1+2+1+2+1$ $+2+1+1+1+1+1<$ $+1+1+1+1+1+1$ $+2+1+1+21+1$

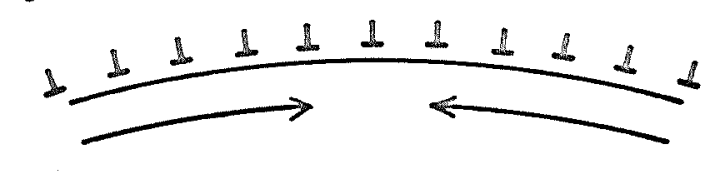

a.

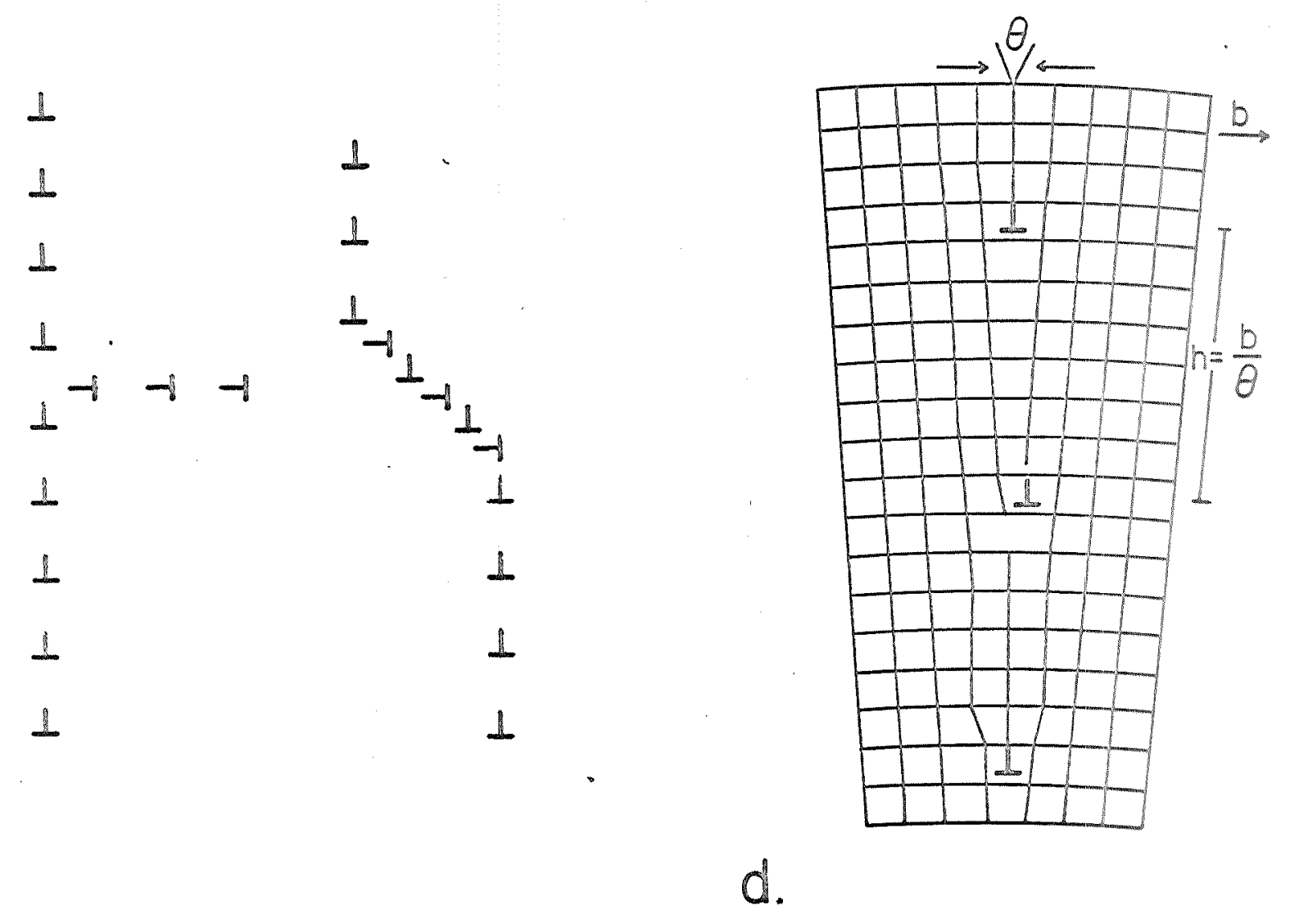



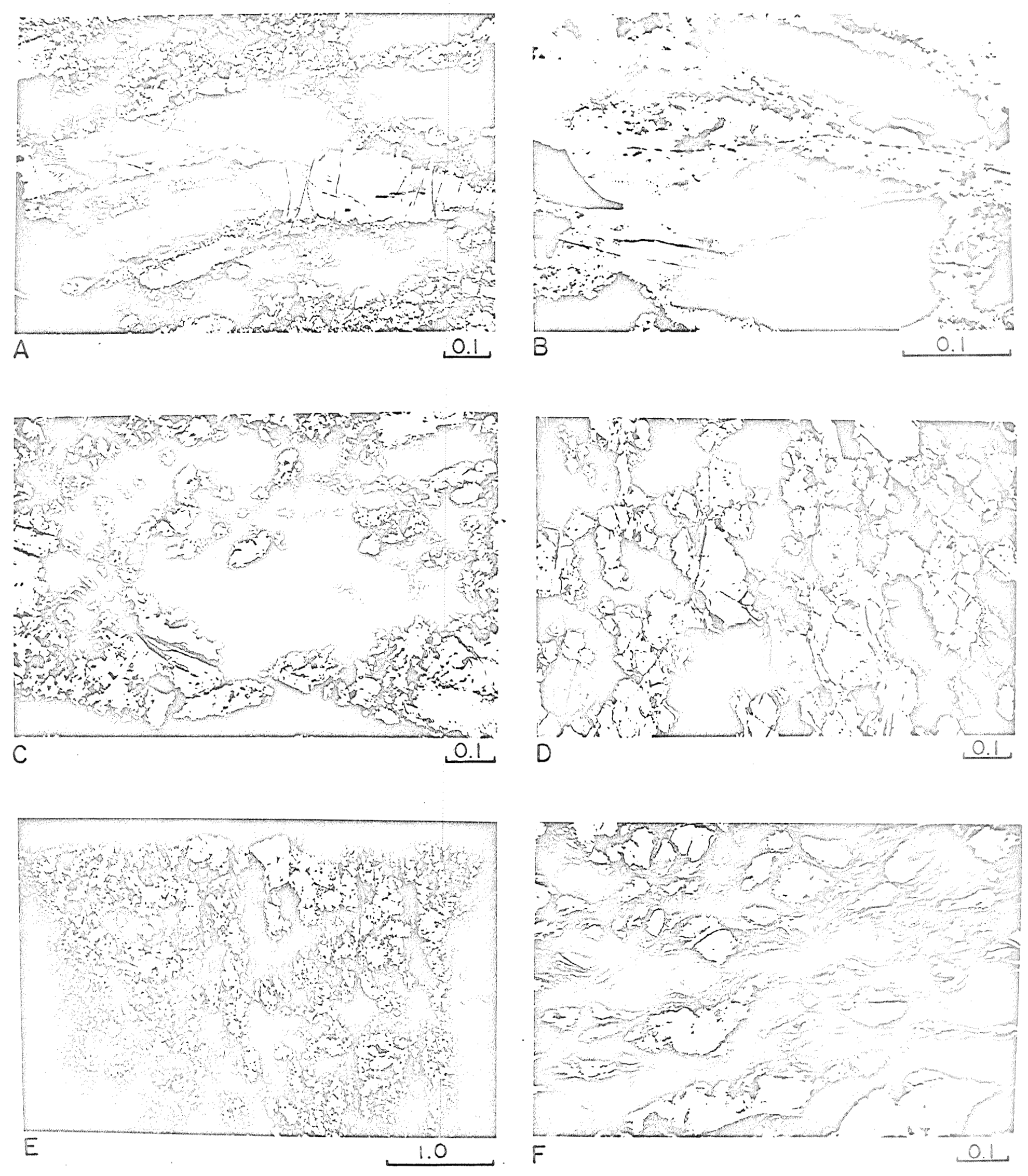


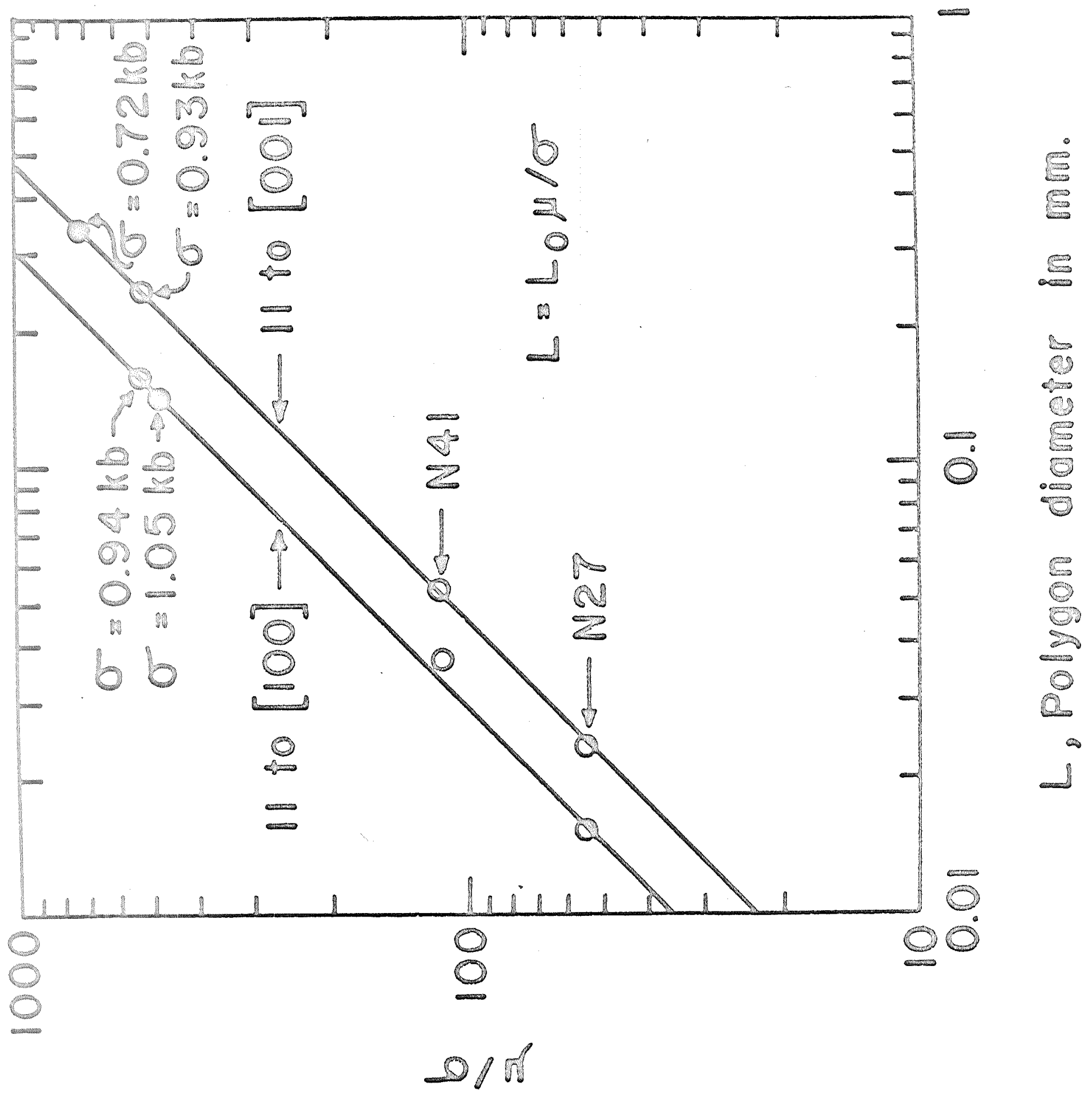



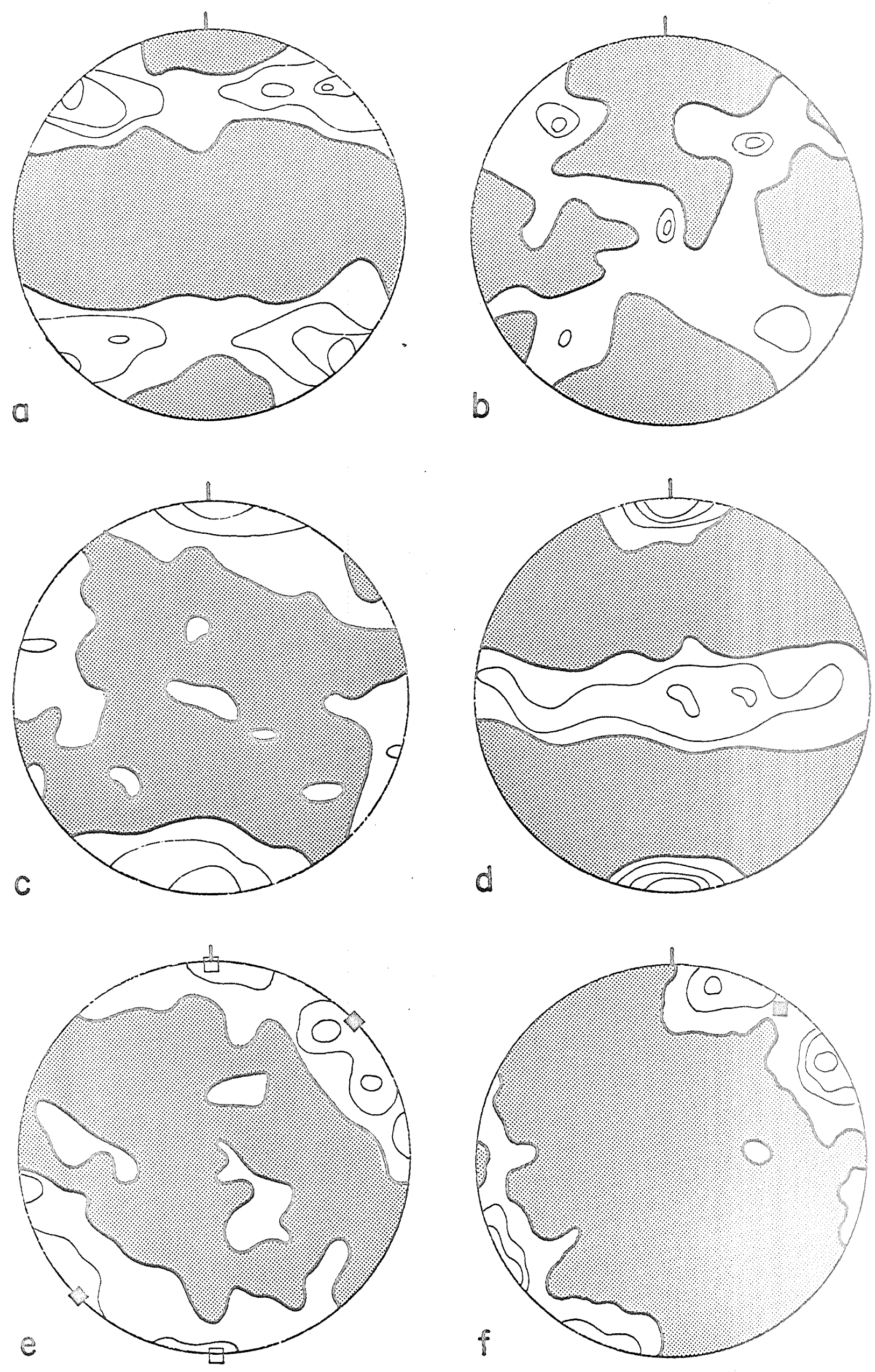

$r \ldots \ldots+b i b$ 


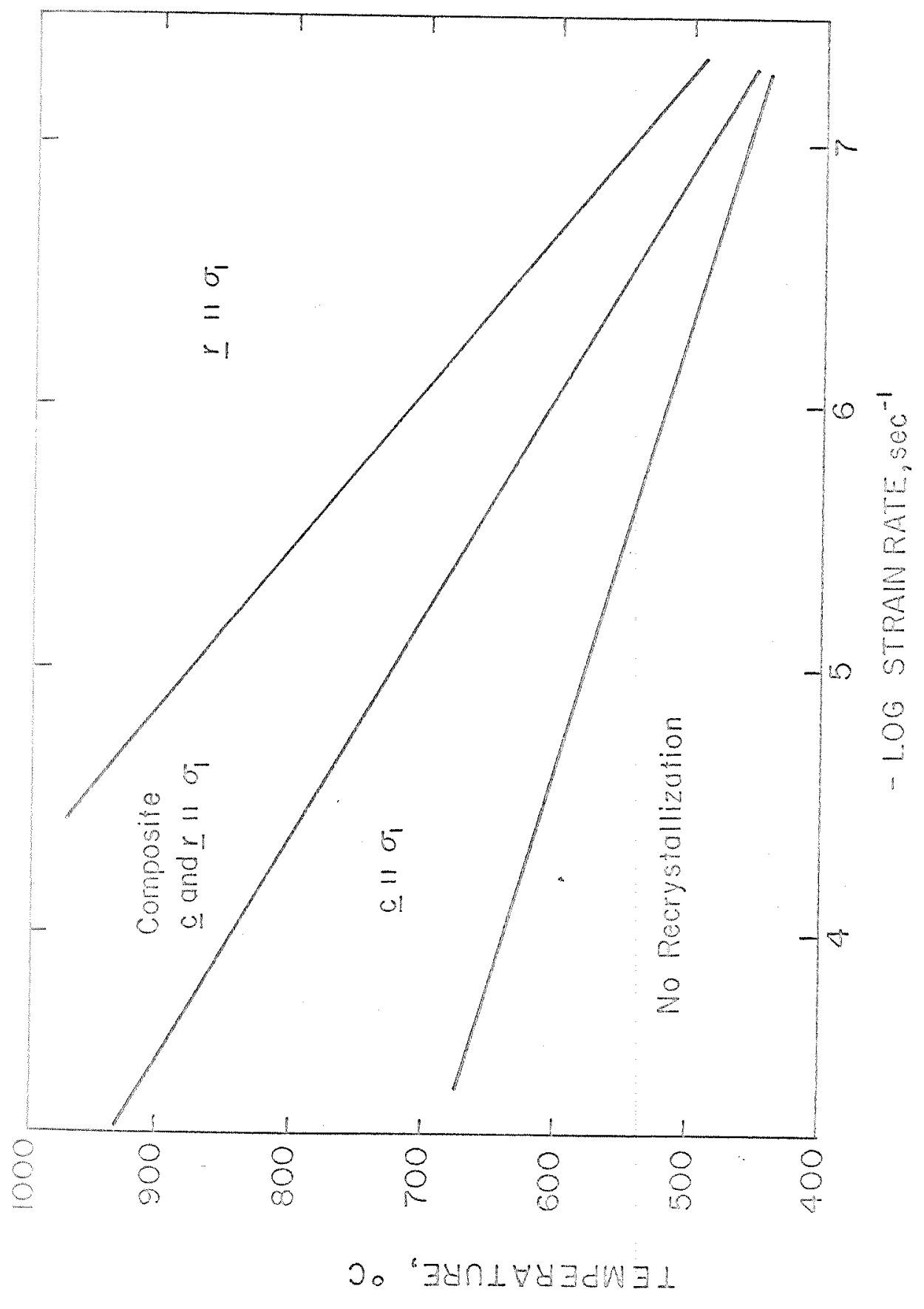



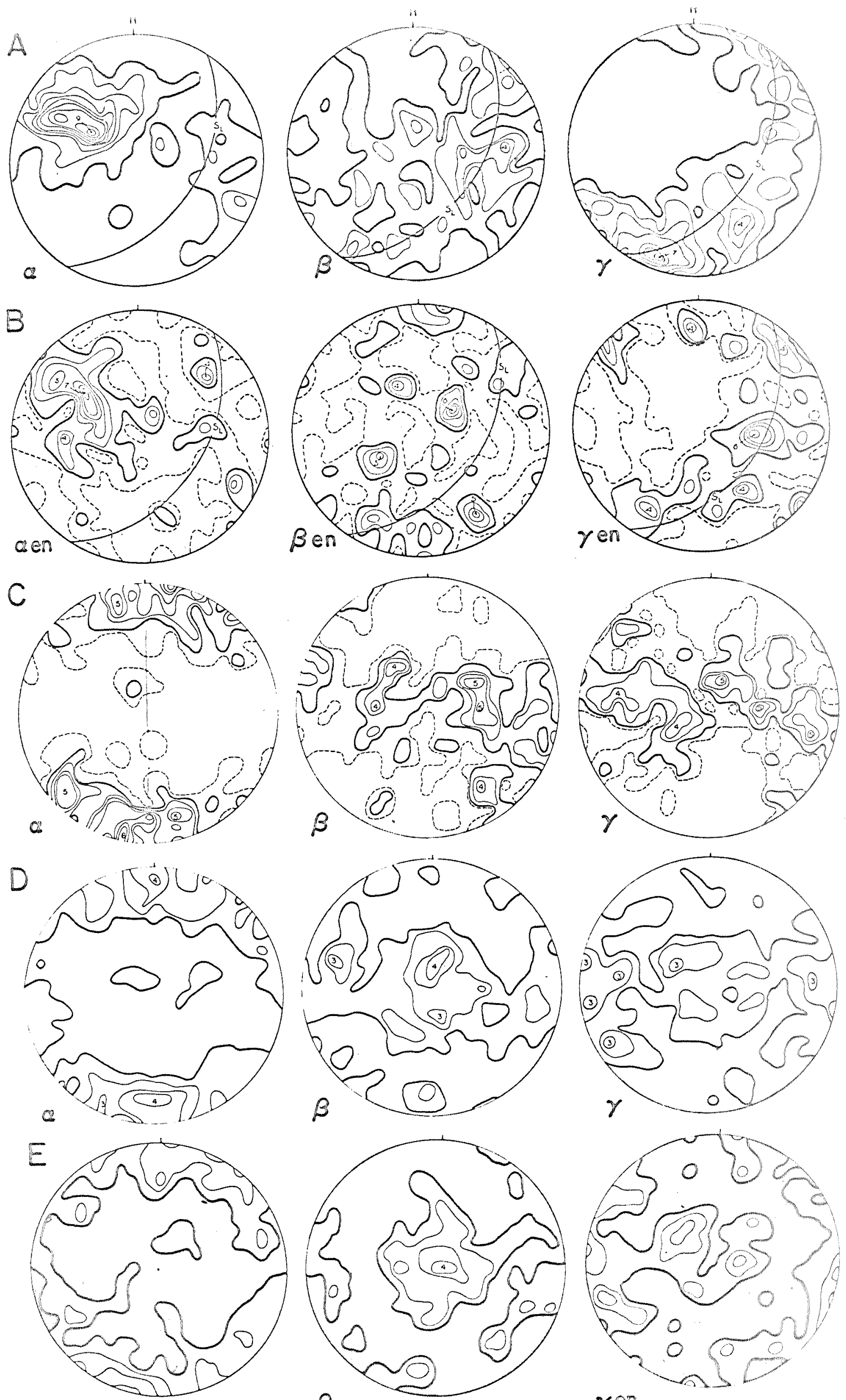

cen
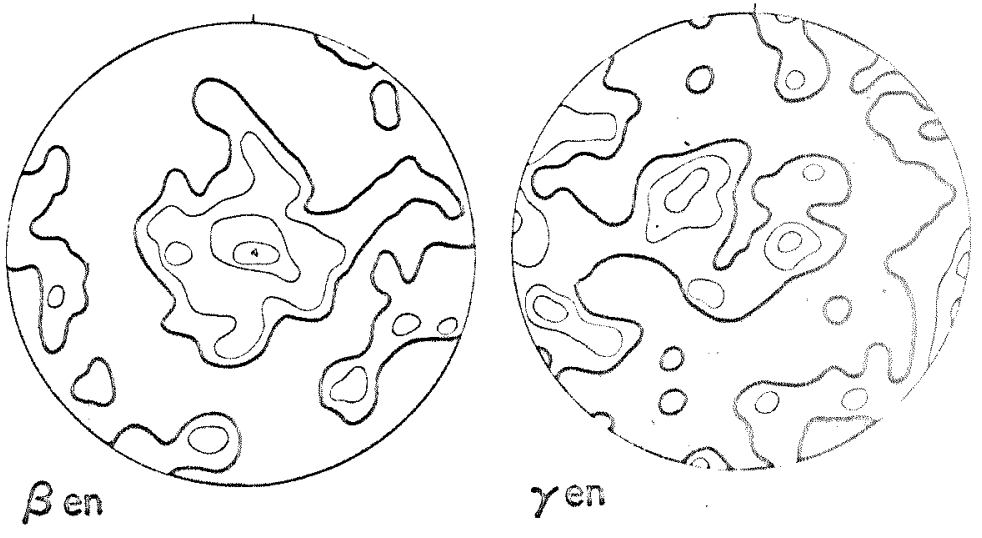


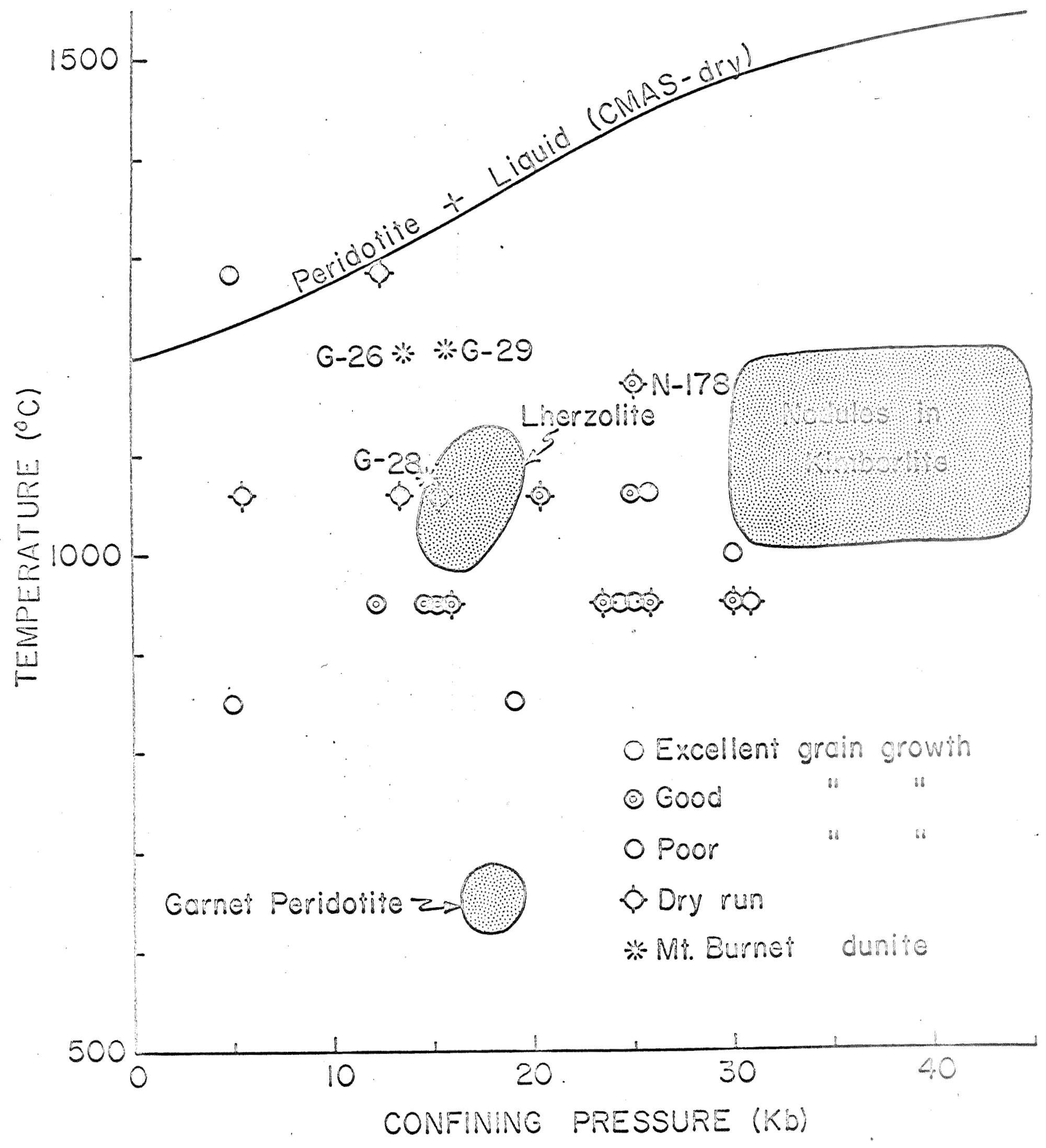

$\because=0$ cos. $=1819$ 